Aged Treg accumulation \& late-onset EAE

\title{
Accumulation of Treg cells is detrimental in late-onset (aged) mouse model of multiple sclerosis
}

\author{
Weikan Wang ${ }^{1}$, Rachel Thomas ${ }^{2}$, Jiyoung $\mathrm{Oh}^{3}$, and Dong-Ming $\mathrm{Su}^{*}$ \\ Department of Microbiology, Immunology, and Genetics, University of North Texas \\ Health Science Center, Fort Worth, TX, 76107, USA.
}

Running Title: Aged Treg accumulation \& late-onset (aged) EAE

Key words: Aging; thymic atrophy; negative selection; regulatory $\mathrm{T}$ cell generation; autoimmunity

1. Graduate School of Biomedical Sciences, Department of Microbiology, Immunology, and Genetics, University of North Texas Health Center, 3500 Camp Bowie Blvd. Fort Worth, TX, 76107, USA

2. Current affiliation: Alcon Research, LLC, Fort Worth, TX 76134 USA; None of the work herein was performed in affiliation with Alcon Research, LLC.

3. Current affiliation: Department of Pediatrics, University of Texas Southwestern Medical Center, Dallas TX 75390 USA.

* Corresponding Author: Dong-Ming Su,

Department of Microbiology, Immunology, and Genetics, University of North Texas Health Center, 3500 Camp Bowie Blvd. Fort Worth, TX, 76107, USA.

Tel. 1-817-735-5186, Fax: 1-817-735-2118,

Correspondence: dongming.su@unthsc.edu

\section{Abbreviations:}

AD: Alzheimer's disease; Ag: antigen BBB: blood-brain barrier; CP: choroid plexus; CNS: central nervous system; DPI: days post-immunization; DT: diphtheria toxin; DTR: diphtheria toxin receptor; EAE: experimental autoimmune encephalomyelitis; LN: lymph nodes; MFI: mean florescence intensity; MOG: myelin oligodendrocyte glycoprotein; MS: multiple sclerosis; pan-: polyclonal; PPMS: primary progressive MS; PRMS: progressive relapsing MS; RRMS: relapsing-remitting MS; SPMS: secondary progressive MS; PT: Pertussis toxin; pTreg or tTreg: peripheral Treg or thymic Treg; sc-RNA-Seq: single-cell RNA sequencing; Teff: $\mathrm{T}$ effector cell; Treg: regulatory $\mathrm{T}$ cell.

Funding: This work was primarily supported by NIH/NIAID grant R01AI121147 to DM. S. and also partially supported by NIH/NIA grant T32 AG020494 to W.W and R.T. 


\section{Aged Treg accumulation \& late-onset EAE}

\section{Abstract}

Although typically associated with onset in young adults, multiple sclerosis (MS) also attacks aged people, which is termed late-onset MS. The disease can be recapitulated and studied in the aged mouse model of experimental autoimmune encephalomyelitis (EAE).

44 The onset of induced EAE is delayed in aged mice, but the disease severity is increased

45 relative to standard EAE in young mice. Given that $\mathrm{CD}^{+} \mathrm{FoxP}^{+}$regulatory $\mathrm{T}$ (Treg) cells

46 play an ameliorative role in MS/EAE severity and the aged immune system accumulates

47 Treg cells, failure of these cells to prevent or ameliorate EAE disease is enigmatic. When

48 analyzing the distribution of Treg cells in EAE mice, the aged mice exhibited a higher

49 proportion of polyclonal(pan) Treg cells and a lower proportion of antigen-specific-Treg

50 cells in their periphery, but lower proportions of pan- and antigen-specific-Treg cells in the

51 central nervous system (CNS). Furthermore, in the aged CNS, Treg cells exhibited a higher

52 plasticity and T effector (Teff) cells exhibited a greater clonal expansion, which disrupted

53 the Treg/Teff balance. Transiently inhibiting FoxP3 expression in peripheral Treg cells

54 partially ameliorated the disease and corrected Treg distribution in the aged mice. These

55 results provide evidence that accumulated aged Treg cells play a detrimental role in

56 neuronal inflammation of aged MS. 


\section{Aged Treg accumulation \& late-onset EAE}

62 Question: $\mathrm{CD}^{+}$regulatory $\mathrm{T}$ (Treg) cells typically play an ameliorative role in multiple 63 sclerosis (MS) onset and severity. However, why aged immune system has accumulated 64 peripheral Treg cells, but the elderly has more severe MS symptoms?

65

66 Findings: Aged Treg cells cannot easily distribute to the CNS of aged EAE mice, and those 67 aged Treg cells that did enter the CNS exhibited increased plastic features. However, 68 transient inhibition of peripherally accumulated Treg cells corrected Treg distribution and 69 partially ameliorated the disease in the aged mice.

70

71 Conclusion and mechanistic insights: Accumulated aged Treg cells within an 72 "inflammaging" condition do not play an ameliorative role but are potentially detrimental 73 for inflamed CNS repair processes in aged EAE mice due to impeding the trafficking of 74 immune cells into the inflamed CNS. 


\section{Aged periphery}

(1) imbalanced CNS-specific

Treg and Tcon

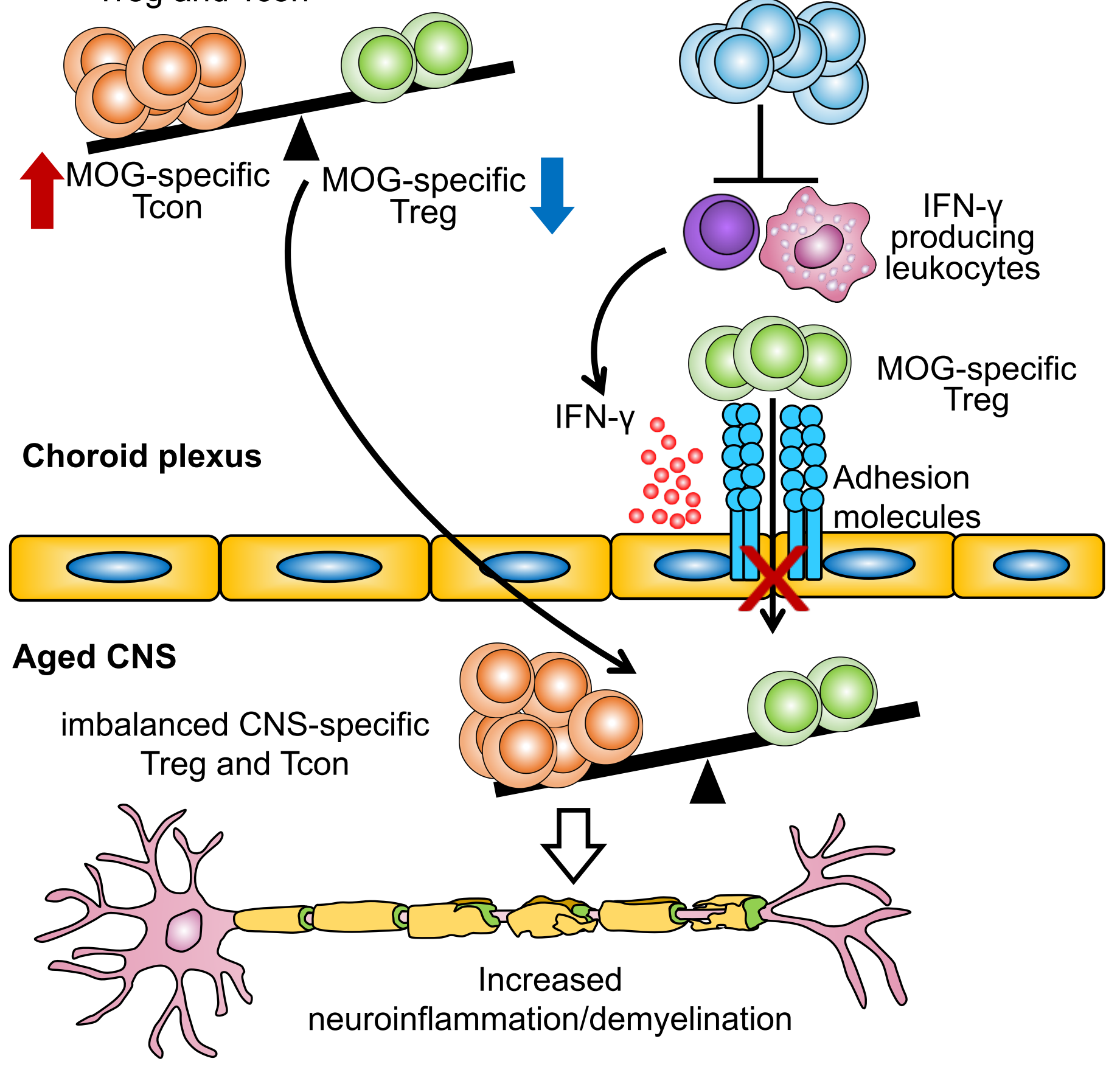

(2) pan-pTreg accumulation 
Aged Treg accumulation \& late-onset EAE

\section{INTRODUCTION}

Neuronal inflammatory diseases are commonly seen in the elderly. These diseases are tightly associated with aberrant immune cell function ${ }^{1,2}$. Human multiple sclerosis (MS) is an autoimmune neuronal inflammatory disease, and its pathology is mainly associated with $\mathrm{CD}^{+}{ }^{+} \mathrm{T}$ effector (Teff) cell-mediated autoimmune demyelination ${ }^{3}$. Although it typically presents with onset in young adults, it either persists in a relapsingremitting manner throughout the life of the patients, or it develops in the elderly (termed: late-onset MS) ${ }^{4,5,6,7}$. MS in the elderly exhibits a severe progression mediated by the aged immune milieu $8,9,10$. To study MS, the mouse model of experimental autoimmune encephalomyelitis (EAE) has been widely used. However, most studies of this disease, either human MS or mouse model EAE, have focused on young subjects and have thus overlooked the age-associated $\mathrm{T}$ cell immune conditions. Therefore, there is insufficient knowledge regarding how MS/EAE is impacted by aged T cells, particularly aged CD4 ${ }^{+}$ Teff and aged $\mathrm{CD}^{+}{ }^{+}$FoxP $3^{+}$regulatory $\mathrm{T}$ (Treg) cells.

$\mathrm{T}$ cell-mediated self-tolerance for controlling autoimmunity ${ }^{11}$, including neuronal autoimmunity, is established and maintained through two primary mechanisms ${ }^{12}$ : depleting self-reactive $\mathrm{T}$ cell clones via thymocyte negative selection ${ }^{13,14}$ and suppressing aberrant immune reaction in the periphery via Treg cells ${ }^{15,16}$, which are mainly generated by the thymus $17,18,19$. The thymus undergoes a progressive age-related involution during aging, which perturbs negative selection, resulting in an increased output of self-reactive Teff cells to the periphery. These self-reactive Teff cells attack self-tissues inducing inflammation, thereby enhancing senescent somatic cell secretions which underlie chronic inflammation (termed senescence-associated secretory phenotype) ${ }^{20,21,22}$ in the elderly (termed inflammaging) ${ }^{23}$. Meanwhile, the aged thymus exhibits relatively enhanced thymic Treg (tTreg) generation ${ }^{24}$ which join the accumulated peripheral Treg (pTreg) pool in the aged periphery 25,26 . This accumulation of polyclonal (pan)-pTreg cells is disadvantageous for anti-infection 27 and anti-tumor 28, 29, 30 immunity, as well as vaccination efficacy in the elderly ${ }^{31}$. In elderly patients with neurodegenerative Alzheimer's disease (AD) or Parkinson's disease, the frequency of peripheral Treg cells and their expression of FoxP3 are increased. However, they do not help to ameliorate these diseases, but rather are correlated with increased disease severity ${ }^{32}$.

Given that Treg cells generally play an ameliorative role in MS disease onset and severity $33,34,35$ and the aged immune system exhibits accumulated pan-pTreg cells, we asked why these cells do not ameliorate severity of MS in elderly patients. Mounting evidence shows that patients over the age of 65 are more likely to have a severe progressive course of MS. Primary progressive (PPMS, disease without remissions) and secondary progressive (SPMS, irreversible damage and disability) are severe and commonly seen in aged patients. However, aged patients are less likely to have a mild course, such as relapsing-remitting MS (RRMS) $(<40 \%)$, compared to their young counterparts of whom $>80 \%$ having RRMS ${ }^{5,36}$. We proposed that the answer to this question is a dichotomy of the Treg cells' role in protection from CNS inflammation within the aged immune system 1,2. We believe that Treg cells have either a detrimental or beneficial role, which is dependent on their location, either inside the CNS or outside the CNS (in the periphery). In addition, the imbalance between Treg and Teff cells ${ }^{37}$ and Treg functional plasticity ${ }^{38}$ within the aged CNS could determine disease severity. 


\section{Aged Treg accumulation \& late-onset EAE}

120

121

122

123

124

125

126

127

128

129

130

131

132

133

134

135

136

137

To verify our hypothesis, we investigated how accumulated aged Treg cells impact late-onset MS using the EAE model in aged mice, by examining Treg distribution inside and outside the CNS, Treg cell antigen specificity to myelin oligodendrocyte glycoprotein (MOG) and pan-antigens, and Treg function-associated molecular profiles during EAE disease in young and aged animals. We also transiently inhibited FoxP3 expression in accumulated pan-pTreg cells in the aged mice and demonstrated a partial amelioration of the disease in the aged mice. Finally, we verified the proposed underlying mechanism and obtained mechanistic insights that accumulated Treg cells residing at a CNS barrier membrane, the choroid plexus (CP), potentially impede the trafficking of immune cells into the inflamed CNS. This results in disruption of the balance between Treg and Teff cells, thereby inhibiting Treg suppression of Teff cell clonal expansion in the inflamed CNS. In addition, CNS-infiltrated Treg cells also showed increased plasticity exhibited by co-expression of IFN- $\gamma$ and/or IL-17A along with FoxP3, which results in reduction of suppressive capacity. Together, our results provide novel evidence that accumulated and compromised aged Treg cells do not play an ameliorative role but are potentially detrimental during late-onset (aged) neuronal autoimmune EAE disease course and severity. 
Aged Treg accumulation \& late-onset EAE

\section{RESULTS}

139 The course of late-onset EAE disease of aged mice exhibited distinct characteristics

Since T cell-mediated autoimmune MS disease typically has an onset in young

Firstly, we used a standard immunization protocol (Hooke Lab etc.) ${ }^{39}$, i.e. immunized the same dosage of MOG peptide and pertussis toxin (PT) to each young and aged C57BL/6 wild-type (WT) female mice (i.e. per mouse based dosage, Fig. S1), which was widely adopted in previous studies. We found that the aged female mice have dichotomous of EAE courses. Some aged mice (about 1/3) had delayed EAE onset but their symptoms became severe after onset, compared to the young group (Fig. S1B, Type-I course), whereas some other aged mice (about 2/3) showed lower debility than the young group and never reached debility score $>3.0$ by 48 days after the first immunization with MOG. Then, we gave them, along with similar numbers of young controls which received the first immunization, a second immunization (Fig. S1A). Interestingly, these aged mice with lower debility immediately showed increased EAE symptoms and became much more severe than their young counterparts. We termed this Type-II course (Fig. S1C).

As the body weight is a critical factor for the dosage administration of drugs, and the aged mice $(30 \sim 40 \mathrm{~g})$ have about $50 \%$ more to double body weight than the young $(20 \sim 25 \mathrm{~g})$ ones (information from our colonies and the Jackson laboratory: https://www.jax.org/jax-mice-and-services/strain-data-sheet-pages/body-weight-chart000664\#, and https://www.jax.org/jax-mice-and-services/strain-data-sheet-pages/bodyweight-chart-aged-b6.). We believe that the inconsistent EAE progression/severity in the age mice might not be due to the inconsistent susceptibilities compared to the young mice, but due to the insufficient $\mathrm{MOG}_{35-55}$ peptide administration. Therefore, we adjusted the $\mathrm{MOG}_{35-55}$ peptide at a body weight dependent manner $(80 \mu \mathrm{g} / 10 \mathrm{~g}$ body weight) and the dosage of PT (100ng/10g body weight) as in Fig. 1A. Then, we found that young and aged mice have a consistent EAE progression, despite different severities (Figs. 1B and C). Therefore, we, for the first time, established a late-onset (aged) EAE model on C57BL/6 WT mice with a body weight corrected $\mathrm{MOG}_{35-55}$ peptide dosage immunization.

Next, we investigated disease progression with the adjusted dosage protocol (Workflow shown in Fig. 1A). We first compared the courses of EAE disease in aged male and female mice (Fig. 1B) and found the two groups had similar EAE onset on 11 or 12days post-immunization (DPI). However, the male group had less severity and great variation of disease symptoms (Fig. 1B, green lines). In contrast, female mice had minimal variation in the disease course with severer disease symptoms (Fig. 1B, blue lines). These characteristics are consistent with observations in human MS disease, in which women are the predominant population of MS patients, and are also consistent with most published reports using female mice for EAE research ${ }^{41,42}$. Therefore, we used female mice for the rest of our study. By comparing young and aged female mice, we determined that aged mice usually had a distinct EAE onset course, i.e. late-onset course. Aged mice had an EAE 
Aged Treg accumulation \& late-onset EAE

183

184

185

186

187

188

189

190

191

192

193

194

195

196

197

198

199

200

201

202

203

204

205

206

207

208

209

210

211

212

213

214

215

216

217

218

219

220

221

222

223

224

225

onset about 12-DPI, which was about 6-day later than EAE onset in young mice (as early as at 6-DPI); however, aged mice developed a more severe disease course (Fig. 1C, blue lines, demonstrated by either EAE scores: left panel, or loss of body weight: right panel). The results provide novel evidence that pathological severity and course of EAE disease in young and old individuals are distinctively different. Although aged mice had a delayed EAE onset after immunization, they suffered from more severe disease progression compared to young mice.

\section{Different distributions of Treg cells between young and aged mice during EAE disease}

Given that Treg cells play a vital protective role in the regulation of MS/EAE severity and progressive disease course $35,40,41,42,43,44,45$, we compared the distributions of pan- and MOG-specific Treg cells, along with Teff (or termed conventional T, Tcon) cells, in the periphery (secondary lymphoid organs, Fig. 2) and the CNS (brain and spinal cord, Fig. 3) between young and aged mice during EAE disease (gating strategies were shown in Fig. S2). We indeed found similarities and differences in the distributions between young and old, which hint at the possibility that Treg cells are involved in the characteristics of EAE disease course.

In the periphery, either in the lymph node (LN) or spleen, the percentage of panTreg cells in aged EAE mice was increased (Figs. 2A and B stripped bars in left and right panels). This is consistent with published reports regarding the accumulation of pTreg cells in aged individuals $25,46,47,48$. However, the percentage of MOG-specific Treg cells in aged EAE mice was decreased (Figs. 2A and B, opened bars in left and right panels). The expression of FoxP3, which is tightly associated with Treg suppressive function, was decreased in MOG-specific Treg cells of aged EAE mice (Figs. 2C and D). In addition, pan-Teff cells were decreased (Fig. 2B, striped bars in middle panel), but MOG-specific Teff cells were not changed in aged EAE mice (Figs. 2B, open bars in middle panel). The results suggest that although pan-Treg cells are increased, MOG-specific Treg cells are reduced. This, coupled with unchanged MOG-specific Teff cells in the aged periphery, results in an imbalance of MOG-specific immunopathogenic and immunoregulatory T cells during aged EAE onset.

In the CNS, including the brain and spinal cord, the percentages of both pan-Treg and MOG-specific Treg cells were decreased in aged EAE mice (Figs. 3A and B top and bottom panels). The results suggest that peripheral Treg cells could not enter the aged, inflamed CNS. The expression of FoxP3 in MOG-specific Treg cells within the aged, inflamed CNS was decreased (Figs. 3C and D), similar to those in the periphery (Figs. 2C and D), suggesting that even if the MOG-specific Treg cells enter the aged CNS, they cannot fully execute their suppressive function. Particularly, both pan- and MOG-specific Teff cells were increased in aged EAE mice (Fig. 3B middle panel), different from those in the periphery (Fig. 2B middle panel), suggesting that both CNS-infiltrated pan- and MOG-specific Teff cells interact with the CNS tissues to participate in inflammation. However, both pan- and MOG-specific Treg cells are less robust in controlling the inflammation in the CNS of aged EAE disease. Interestingly, such a discrepancy between the young and aged mice Treg cells was not observed prior to EAE onset (Fig. S3), 
Aged Treg accumulation \& late-onset EAE

226

227

228

229

230

231

232

233

234

235

236

237

238

239

240

241

242

243

244

245

246

247

248

249

250

251

252

253

254

255

256

257

258

259

260

261

262

263

264

265

266

267

indicating that the imbalanced Treg distribution in the aged mice developed during EAE disease.

Together, these findings can help explain one of the reasons that aged mice have a late-onset but more severe EAE pathology. Delayed onset is probably due to the pTreg accumulation, while the more severe progressive disease course is perhaps due to impaired trafficking of both pan- and MOG-specific Treg cells into the CNS during EAE disease. In other words, although pan-pTreg cells are accumulated in the periphery of aged mice, it is likely that they cannot easily enter into the aged, inflamed CNS during EAE disease.

\section{CNS-infiltrated Treg cells in late-onset EAE of aged mice exhibited dysfunctional molecular profiles}

Treg cells can possess relatively unstable features ${ }^{49,50}$, including down-regulation of FoxP3 expression ${ }^{16,51}$ as confirmed in our aged late-onset EAE mouse model (Figs. 2D, 3D), and co-expression of ifng or ill7a toward Th1-like or Th17-like plastic conversion ${ }^{52}$, ${ }^{53}$ upon autoimmune stimulation ${ }^{16,51,54}$. This leads to functional plasticity, resulting in increased pathology and reduced suppressive capacity ${ }^{16,53}$. We believe that this unstable phenotype will likely be more prominent in the aged microenvironment. To evaluate these function-related molecular profiles, we analyzed the expression of ifng and $i l 17 a$ genes in CNS-infiltrated Treg cells of EAE mice at the single-cell level (Fig. 4A). We compared $\mathrm{CD}^{+} \mathrm{FoxP}^{+}$Treg cells in the young and aged CNS (Fig. 4B) during EAE disease and found that expression of ifng and il17a was indeed increased in the CNS-infiltrated aged Treg cells (Fig. 4C). In addition, we noticed that $\mathrm{CD} 8^{+} \mathrm{T}$ cells in the $\mathrm{CNS}{ }^{55}$, particularly, activated or pathogenic $\mathrm{CD} 8^{+} \mathrm{T}$ cells, indicated by expressions of ifng and $i l 17 a$, which potentially lead to autoimmune encephalomyelitis ${ }^{57,58}$, presented increased ifng and $i l 17 a$ expressions in the aged CNS with EAE disease (Fig. 4D). IL-17A secreting CD8 ${ }^{+} \mathrm{T}$ cells, termed Tc17 cells, in the CNS support Th17-mediated autoimmune encephalomyelitis ${ }^{56}$, ${ }^{57}$. These results imply that aged Treg cells, which have infiltrated into the CNS after EAE onset, could have reduced capacity to suppress neuronal inflammation.

\section{Clonal expansions of CNS-infiltrated Teff cells in late-onset EAE in aged mice was increased}

To assess whether CNS-infiltrated aged Treg cells have reduced suppressive capacity, a comparison of Teff cell clonal expansions in the EAE CNS can shed some light. We therefore analyzed clonal expansions in the CNS-infiltrated Teff cell pool along with the Treg cell pool based on TCR sequence similarity via TCR $\alpha \beta$ immune profile analysis with the single-cell RNA sequencing (sc-RNA-Seq) approach (Fig. 5). The capacity of Treg cells to suppress clonal expansions of various Teff cells influences Teff cell-induced CNS inflammation. The results showed that aged Teff cells had a greater clonal expansion, compared to the young (Fig. 5A top pies and Fig. S4 left two columns), and the expanded Teff clones (both total expanded clones and top 10 expanded clones) occupied a higher proportion of the Teff pool (Fig. 5B left panels) in the aged, inflamed CNS. However, although Treg cells can proliferate in vivo ${ }^{58,59}$, aged Treg clones showed the same 
Aged Treg accumulation \& late-onset EAE

290

291

292

293

294

295

296

297

298

299

300

301

302

303

304

305

306

307

308

309

310

311

expansion as in the young (Fig. 5A bottom pies, 5B right panels and Fig. S4 right two columns). Together, aged Teff cells are more activated in the aged, inflamed CNS during EAE disease, which is potentially due to the insufficient suppression by Treg cells. The results also indicate that the expansive capacity of CNS-infiltrated Treg cells in aged EAE mice is not reduced compared to their young counterparts.

\section{EAE severity was mitigated after transient inhibition of FoxP3 expression in pan- pTreg cells in the aged mice}

Accumulation of pan-pTreg cells in aged individuals $25,46,47,48$ was demonstrated to be harmful during neurodegenerative disease $\mathrm{AD}$, since transiently inhibiting FoxP3 expression in the accumulated Treg cells attenuated the pathology ${ }^{60}$. However, it is unknown whether this accumulation is detrimental or beneficial in late-onset MS/EAE. Given that aged EAE disease occurs with accumulated Treg cells in the periphery (Fig. 2B), but less in the aged, inflamed CNS (Fig. 3B), we hypothesized that the cellular trafficking may be impeded by the accumulation outside the CNS. Therefore, transient inhibition of FoxP3 expression in accumulated pTreg cells in the aged mice could mitigate late-onset EAE symptoms and pathology. Therefore, we administrated 5-doses of P300i, which can impair Treg suppressive activities by inhibiting FoxP3 expression without affecting Teff cell responses ${ }^{61}$ and has been used to transiently and partially suppress panpTreg cells residing outside the CNS ${ }^{60}$, to aged mice beginning on 12-DPI (Fig. 6A). We evaluated the percentages of Treg cells (Fig. 6B left panel and Fig. S5A) and expression level (via mean florescence intensity, MFI) of FoxP3 (Fig. 6B right panel and Fig. S5B) in the peripheral blood at three time points (Fig. 6A three red arrowheads indicate tests, i.e. before and after the P300i injections). The results show that the pan-pTreg cells decreased one day after the last P300i injection, but returned to normal levels after 12 days (Fig. 6B). This confirms that the inhibition was effective and transient, and Treg cells had restored FoxP3 expression after the pharmaceutical inhibitory effects decay over time.

Regarding the severity of EAE disease after transient inhibition of FoxP3 in accumulated pan-pTreg cells in the aged mice, we evaluated EAE symptoms (disease scores and demyelination) and found that the severity was attenuated in the aged P300itreated group (Fig. 6C black line and Fig. 6D rightmost image). Although the improvement did not restore to the same level as the young group, it was significant. The results provide evidence that the accumulation of aged pan-pTreg cells in the periphery is not beneficial but rather detrimental to late-onset MS/EAE in aged individuals.

To reconfirm aforementioned results that impairing the accumulated pan-pTreg in the aged mice can rescue the EAE symptom, we introduced aged Foxp3-DTR/EGFP mice (termed DTR mice) for late-onset EAE model. DTR mice have FoxP3 ${ }^{+}$Treg cells expressing diphtheria toxin receptor (DTR) and thus Treg cells can be transiently depleted after administrating diphtheria toxin (DT) ${ }^{62}$. Therefore, we i.p. injected DT once to the aged-DTR EAE mice with at $50 \mu \mathrm{g} / \mathrm{kg}$ body weight on 12 -DPI. We evaluated the percentages of Treg cells in the peripheral blood one day before the injection (11-DPI), one day after the injection (13-DPI) and 16 days after the injection (28-DPI). As expected, peripheral blood Treg cells were completely depleted one day after the DT injection and restore to normal level 16 days after the injection (Fig. S6A and B). As a result, EAE 
Aged Treg accumulation \& late-onset EAE

312 symptom presented a partially alleviated trend in the aged-DTR mice with transient pTreg

313 depletion (Fig. S6C).

314

Transient inhibition of FoxP3 expression in the accumulated pan-pTreg cells was a potential mechanism of the late-onset EAE alleviation in aged mice

We wanted to elucidate the underlying mechanism by which late-onset EAE alleviation occurred in aged mice via transient inhibition of FoxP3 expression. Based on a published report, accumulated Treg cells, which are adherent to the barrier sites including the blood-brain barrier (BBB) and the CP of the CNS, suppress IFN $\gamma$-secreting cells and potentially result in hampered trafficking of monocytes and antigen (Ag)-specific Treg cells into the inflamed CNS ${ }^{63}$. Transient, rather than permanent, inhibition of FoxP3 expression in the accumulated pTreg cells mitigated $\mathrm{AD}^{60}$ due to facilitated trafficking of anti-inflammatory monocytes and Treg cells during CNS inflammation. We believe this is likely the case with late-onset MS/EAE. Thus, we investigated the expression of IFN- $\gamma$ in $\mathrm{CP}$-adherent $\mathrm{CD} 45^{+}$hematopoietic cells and the proportions of CNS-infiltrated Treg and Teff cells with/without the transient inhibition in the aged mice.

Once we transiently inhibited FoxP3 expression in the accumulated pan-pTreg cells in the aged mice, one day after the last treatment (Fig. 6A, the $2^{\text {nd }}$ test red arrow), we found that expression of IFN- $\gamma$ was increased in the CP-adherent hematopoietic CD45 ${ }^{+}$cells (Fig. 7A black line in the pick box). We also determined the impact on Treg CNS-infiltration after the pan-pTreg transient inhibition of pan-pTreg cells. The results showed that both the percentages of pan-Treg cells (Figs. 7B left panel and C black striped bar in left panel) and MOG-specific Treg cells (Figs. 7B right panel and $\mathrm{C}$ black open bar in left panel) were increased in the inflamed CNS of aged mice. The lack of change in FoxP3 expression in CNS-infiltrated Treg cells (Figs. 7D and E) with/without transient inhibition may indicate that the drug P300i does not affect CNS-infiltrated Treg cell function. In addition, increased Treg cells in the CNS could either suppress Teff cells (Fig. 7C middle panel) or increase the ratio of Treg versus Teff cells (Fig. 7C right panel). This ratio was previously imbalanced during late-onset EAE disease (Fig. 3B bottom panel). Likewise, this partially restored Treg to Teff balance in the aged EAE CNS was also observed in the aged-DTR EAE mice with transient pTreg depletion (Fig. S6D).

These results suggest that the potential underlying mechanism of the mitigation of late-onset EAE severity via the transient inhibition of FoxP3 expression in the accumulated pan-pTreg cells in aged mice is very similar to the mechanism using this method in mitigation of $\mathrm{AD}$ pathology ${ }^{60}$. It is due to easing the cellular trafficking of antiinflammatory cells ${ }^{63}$, including not only pan- and MOG-specific Treg cells but likely other anti-inflammatory monocytes, such as monocyte-derived anti-inflammatory M2 macrophages, into the inflamed CNS to enhance the anti-inflammatory capacity. 
Aged Treg accumulation \& late-onset EAE

\section{DISCUSSION}

353 Typically, human MS disease develops in young (20 - 40 years old) females and 354 presents with at least four clinical sub-types. Two of them, progressive-relapsing MS 355 (PRMS) and RRMS, have relatively mild symptoms, and are often seen in young patients 356 (80\% - 90\%). However, the other two, PPMS and SPMS, have severe symptoms, and are often seen in aged ( $>65$ years old) patients ( $29 \%$ for PPMS and $\sim 26 \%$ for SPMS), while young patients only account for 10\% PPMS and rarely exhibit SPMS ${ }^{5}$. Late-onset MS in the elderly has been reported ${ }^{4,5,6,7}$, and the mean age of the MS population is rising ${ }^{5}$. It

360

361 was reported that $14 \%$ of total MS patients were 65 years and older in $2010^{64}$. The severe symptoms in the aged patients are more or less attributed to Treg cell function, since Treg cells are regarded as protective cells, which combat IFN- $\gamma$-producing and IL-17-producing $\mathrm{CD}^{+}$pathogenic cells $35,40,41,42,43,44,45$, and pathogenic $\mathrm{CD}^{+} \mathrm{T}$ cells involved in the MS lesion ${ }^{65,66}$.

Ample evidence shows that Treg cells play an ameliorative role in MS/EAE disease onset and severity $33,34,35$. Transferring Treg cells into MOG-induced EAE mice attenuated disease ${ }^{67}$ and EAE severity correlated inversely with the frequency of MOG-specific Treg cells ${ }^{68}$. However, accumulation of Treg cells ${ }^{25}$ with enhanced suppressive function ${ }^{26}$ in aged individuals is accompanied with severe symptoms in aged mice with late-onset EAE disease (Fig. 1). This is not consistent with the notion that Treg cells play a role in suppressing uncontrolled immune reactions. This inconsistency encouraged us to investigate the underlying mechanism.

$\mathrm{CD}^{+} \mathrm{FoxP}^{+}$Treg cells primarily act to suppress Teff cell-mediated aberrant antigen-specific and non-specific immune responses. Accumulation of Treg cells in the elderly is disadvantageous for fighting infection, cancer, neurodegenerative and autoimmune diseases. In protection and recovery from CNS inflammatory disorders, such as $\mathrm{AD}$, one of the age-related neuroinflammatory diseases, excessive Treg cells were shown to play a detrimental role ${ }^{60}$. This is probably due to Treg cell distribution either inside the CNS or in the periphery ${ }^{1,2}$, in addition to the existence of distinct Treg subsets ${ }^{69,70}$. Herein, using an aged EAE mouse model that resembles aged human MS disease, we found that the aged EAE mice had a different distribution of pan- and MOG-specific Treg cells compared to their young counterparts. Specifically, aged mice exhibited a high proportion of pan-Treg and a low proportion of MOG-specific Treg cells in their periphery, but low proportions of both pan- and MOG-specific Treg cells in the inflamed CNS (Figs. 2 and 3). Accumulation of Treg cells outside the CNS and residing at the CNS-periphery boundaries, the BBB and CP, could impede immune cell, including Treg cell, trafficking into the inflamed CNS for the recovery ${ }^{60,63}$.

Treg cells are unstable and plastic, and this is especially observable during loss of FoxP3 expression in a proportion of mature Treg cells ${ }^{71}$, and the plastic characteristics are exhibited by the production of pro-inflammatory cytokines IFN- $\gamma$ or IL17, along with FoxP3 expression. These Treg cells acquire an effector-like phenotype, and they are able to induce, rather than suppress, autoimmunity. These cells are commonly seen in the autoimmune-prone NOD background mice and diabetic patients ${ }^{52,72}$, as well as in MS patients (mouse EAE setting) ${ }^{73,74}$. We found that in the aged inflamed CNS Treg cells exhibited higher plasticity than in the young counterparts, observed as co-expression of 
INF- $\gamma$ and/or IL-17 with FoxP3 (Fig. 4), which potentially results in reduced suppressive function and increased pathology 16,53 . This could contribute to the higher clonal expansion of Teff cells in this inflamed CNS (Fig. 5). Furthermore, this also results in disruption of a normal Treg/Teff balance. In addition to self-antigen-driven inflammatory autoimmune stimulation ${ }^{16,51}$, the age-related, chronic, systemic inflammation (inflammaging) may play a synergistical role to enhance Treg plasticity in aged EAE mice compared to young counterparts. However, this area needs further investigation.

It is a difficult and complex task to overcome the accumulation of Treg cells in the elderly as a therapeutic strategy for neuroinflammatory disease. Transient inhibition of FoxP3 expression in the accumulated peripheral $\mathrm{CD}^{+}{ }^{\mathrm{FoxP}} 3^{+}$Treg cells in aged individuals is one option, which was used in $\mathrm{AD}$ and displayed improvement of amyloidbeta plaque clearance, amelioration of neuroinflammation, and recovery of cognitive decline demonstrated in an AD mouse model ${ }^{60}$. We transiently inhibited accumulated peripheral Treg cells in aged mice, which partially ameliorated the EAE disease and corrected Treg distribution (Figs. 6 and 7). The mechanism is probably the accumulated CP-resident Treg cells suppressing INF- $\gamma$ producing cells, such as Th1 $\mathrm{CD} 4^{+} \mathrm{T}$ cells outside the CNS, which directly block the gateway ${ }^{60}$ for homeostatic leukocyte trafficking into the CNS ${ }^{75,76}$. IFN- $\gamma$ is required for activation of the brain's CP for CNS immune surveillance and repair ${ }^{63,76}$. For example, immunization with a myelin-derived antigen was reported to activate the brain's CP via inducing the CP to express IFN- $\gamma$ and attract Th1 cells, thereby enhancing recruitment of immunoregulatory cells to the CNS to achieve attenuation of neuroinflammatory progression in a mouse model ${ }^{77}$. Interestingly, a complete depletion of pTreg cells, even though in a transient manner, did not seemingly so efficiently alleviate EAE symptom in the aged mice (Fig. S6C) as partial inhibition of pTreg cells (Fig. 6C), but this undefined result remains to be further investigated.

Although $\mathrm{CD}^{+} \mathrm{T}$ cells, both $\mathrm{CD} 4^{+}$Teff and $\mathrm{CD}^{+} \mathrm{FoxP}^{+}$Treg cells, are the traditional primary actors in MS/EAE disease pathogenesis and immunoregulation, emerging evidence shows that $\mathrm{CD} 8^{+} \mathrm{T}$ cells also have roles in both immunopathology and immunoregulation, either to exacerbate or mitigate brain inflammation during CNS autoimmunity ${ }^{78,79}$. Regarding the MS/EAE immunopathogenesis aspect, myelin-specific $\mathrm{CD}^{+} \mathrm{T}$ cells exacerbate brain, though not spinal cord, inflammation via a Fas liganddependent mechanism to promote lesion formation in the brain ${ }^{80}$. In addition, IL-17A secreting $\mathrm{CD}^{+} \mathrm{T}$ cells, termed $\mathrm{Tc} 17$ cells, in the CNS support Th17 cell-mediated autoimmune encephalomyelitis ${ }^{56,57}$. In aged neurogenic niches that comprise neural stem cells, $\mathrm{CD} 8^{+} \mathrm{T}$ cells are increased to inhibit the proliferation of neural stem cells ${ }^{55}$. This is a disadvantage for the recovery of demyelinating plaques in aged MS/EAE disease. Our results show that IL-17 $\mathrm{A}^{+} \mathrm{CD} 8^{+}$cells were increased in the aged EAE CNS (Fig. 4D), which was consistent with severe symptoms and pathology in aged EAE mice. However, regarding the MS/EAE immunoregulation aspect, although the concept of $\mathrm{CD} 8^{+}$Treg cells is not unanimously accepted, the function of $\mathrm{CD} 8^{+}$Treg cells in MS/EAE has received attention ${ }^{81,82,83}$. The main focus of studies in $\mathrm{CD} 8^{+}$Treg cells in MS/EAE is in young patients or young animals, and there are many unanswered questions regarding how these 440 cells play a role in aged CNS autoimmune inflammation in the elderly. Therefore, the function of these cells in the elderly need to be investigated. 
bioRxiv preprint doi: https://doi.org/10.1101/2021.12.16.472986; this version posted December 17, 2021. The copyright holder for this preprint (which was not certified by peer review) is the author/funder. All rights reserved. No reuse allowed without permission.

\section{Aged Treg accumulation \& late-onset EAE}

441 In summary, the results herein provide insights into how accumulated aged 442 polyclonal $\mathrm{CD}^{+} \mathrm{FoxP}^{+}$Treg cells in an inflammatory condition do not ameliorate but are 443 detrimental for CNS repair processes in neuronal inflammation of aged MS demonstrated 444 in the animal model EAE.

445

446 
Aged Treg accumulation \& late-onset EAE

\section{METHODS}

\section{Mice and animal care}

C57BL/6 wild-type (WT) mice were used. Aged (18 - 20 months old) mice were ordered from the National Institute on Aging, aged rodent colonies. Control young WT mice were 2 - 3 months old. FoxP3-DTR/GFP mice (Stock No: 016958) were obtained from the Jackson laboratory. All mice were maintained under specific pathogen-free conditions in the animal facilities at the University of North Texas Health Science Center. All animal experiments were performed in compliance with protocols approved by the Institutional Animal Care and Use Committee of the University of North Texas Health Science Center (IACUC-2018-0014, 2021-0020), in accordance with guidelines of the National Institutes of Health.

\section{Late-onset $\mathrm{EAE}$ mouse model and disease score determination}

EAE was induced as shown in Fig. 1A. Briefly, MOG $35-55$ peptide (WatsonBio Sciences) was emulsified in Complete Freund's Adjuvant (Sigma-Aldrich F5881) and given as onetime subcutaneous (s.c.) injection into the upper and lower backs of mice $\left(80 \mu \mathrm{g} \mathrm{MOG}_{35-55}\right.$ peptide/10g body weight). Pertussis toxin (PT) (List Biologicals, Cat\#179A) was intraperitoneally (i.p.) injected on days 0 and 1 (100ng PT/10g body weight). Mice were monitored daily for EAE symptoms and body weight changes. EAE scores were assigned in supplemental Table S1.

\section{Transient inhibition of FoxP3 expression in pan-pTreg cells and transient depletion of pTreg cells}

As shown in Fig. 6A, 12 days after EAE induction in young and aged WT mice, P300i (C646; Tocris Bioscience, Cat\# 4200) was i.p. injected at $8.9 \mathrm{mg} / \mathrm{kg}$ body weight per day for 5 consecutive days $(5 \mathrm{x})$ in one of the aged mouse groups similar to published protocol ${ }^{60}$. Vehicle-injected young and aged mice were controls. The dynamic changes of Treg cell frequencies and Foxp3 expression were monitored at three-time points as denoted by red arrows in Figure 6A.

12 days after EAE induction in young and aged DTR mice, DT (Sigma-Aldrich, Cat\#D0564) was i.p. injected at $50 \mu \mathrm{g} / \mathrm{kg}$ body weight to one of the aged-DTR mouse groups. Vehicle-injected young and aged mice were controls.

\section{Cell isolation from the CNS and the CP}

For mononuclear cell isolation from the brains and the spinal cords, euthanized mice were transcardially perfused with $20 \mathrm{ml}$ of PBS. CNS tissues were minced and digested with $2 \mathrm{mg} / \mathrm{ml}$ collagenase D (Roche, Cat\# 11088858001) and 28U/ml DNase I (Invitrogen, Cat\# 18068015) in RPMI-1640 at $37^{\circ} \mathrm{C}$ for $45 \mathrm{~min}$, followed by percoll (Sigma-Aldrich, Cat\# P1644) gradient centrifugation per our previous method ${ }^{84}$. For cell isolation from the brain $\mathrm{CP}, \mathrm{CP}$ tissues ( 5 mice per group) were collected from the lateral, third and fourth ventricles of the brain, then digested at $37^{\circ} \mathrm{C}$ for $40 \mathrm{~min}$ in $2 \mathrm{mg} / \mathrm{ml}$ collagenase-D/PBS with pipetting. 
Aged Treg accumulation \& late-onset EAE

490

491

492

493

494

495

496

497

498

499

500

501

502

503

504

505

506

507

508

509

510

511

512

513

514

515

516

517

518

519

520

521

522

523

524

525

526

527

528

529

530

531

532

533

534

535

Tetramer-based flow cytometric assay of pan-and MOG-specific Treg and Teff cells and IFN-rproducing cells at the $\mathrm{CP}$

Single-cell suspensions from the LN, spleen, and the CNS of mice were stained with extracellular fluorochrome-conjugated CD markers (Biolegend), along with APCconjugated $\mathrm{MOG}_{38-49} \mathrm{I}_{-} \mathrm{A}^{\mathrm{b}}$ tetramer $(\mathrm{NIH}$ tetramer core, peptide sequence: GWYRSPFSRVVH) and Brilliant Violet 421-conjugated human CLIP $87-101 \mathrm{I}^{\mathrm{A}} \mathrm{A}^{\mathrm{b}}$ tetramer as a control (peptide sequence: PVSKMRMATPLLMQA). Then, cells were fixed and permeabilized using the fixation and permeabilization kit (eBioscience, Cat\# 00-5523-00) for intracellular staining of PE-conjugated anti-FoxP3 (eBioscience Cat\# 12-5773-82) per the company's instruction. Data were analyzed using FlowJo ${ }^{\text {TM }}$ v10 software and particularly, MFIs were defined as the medians of fluorescence intensities of the conjugated fluorochromes of the antibodies.

Cells isolated from the CP were incubated with PMA $(5 \mathrm{ng} / \mathrm{ml})$, ionomycin $(500 \mathrm{ng} / \mathrm{ml})$, and Protein Transport Inhibitor $(0.7 \mu \mathrm{L} / \mathrm{mL}$, BD Biosciences. Cat\# 51-2092KZ) for 5hrs, followed by extracellular staining with PerCP/Cy5.5 conjugated anti-CD45 (Biolegend, Cat\# 103132) and intracellular staining with APC-conjugated anti-IFN- $\gamma$ (Biolegend, Cat\# 505810).

\section{Single-cell RNA-seq of CNS T cells for analysis of transcriptome profile and TCR copy number-based $T$ cell clonal expansion}

Mononuclear cells were isolated from the CNS of three young and three aged EAE mice. Cells were stained with anti-CD3-APC (Biolegend, Cat\#100236) and anti-CD11bBrilliant Violet 711 (Biolegend, Cat\#101242), then sorted on Sony SH800 Cell Sorter to collect $\mathrm{CD}^{+}{ }^{+} \mathrm{CD} 11 \mathrm{~b}^{\text {-neg }} \mathrm{T}$ cells, followed by gene expression (GEX) and TCR V(D)J library preparation and sequencing with the 10x Genomics Chromium Single Cell 5' GEM, Library \& Gel Bead Kit v2 (10x Genomics, Cat\#1000287). The cDNA was amplified using the same kit. Products were purified using Ampure XP beads and quality was controlled using Agilent Tapestation and Qubit 4 fluorometer. TCR target enrichment was done by Chromium Single Cell Mouse TCR Amplification kit (10x Genomics, Cat \#1000254). TCR V(D)J and GEX libraries were constructed by the Library Construction Kit (10x Genomics, Cat \#1000190) with Dual Index Kit TT Set A. Sequencing was on an Illumina NovaSeq 6000 according to $10 \mathrm{x}$ Genomics sequencing protocol recommendations.

Fastq files (Cell Ranger, version 6.0.2, 10xGenomics provided mm10 reference genome), Cloupe file, and Vloupe files were generated for the downstream analysis. The t-SNE plots of T cells were visualized by 10x Genomics Loupe Brower 5.0 and T cells were classified into three groups, including CD8 T cells, CD4 Teff cells and CD4 Treg cells. Numbers of unique molecular identifiers (UMI) of Ifng and Ill7a were used to determine the gene expression levels in every single cell in the Treg and CD8 $8^{+} \mathrm{T}$ cell populations. 10x Genomics Loupe VDJ Brower 4.0 was used to output the clonotypes of $\mathrm{CD}^{+}$Teff and Treg cells by aggregating the Cloupe file and Vloupe file of each sample. Each clone was determined by the CDR 3 regions of paired TCR $\alpha$ and TCR $\beta$ chains. Based on TCR sequence similarity, clones with clonal size greater than 2 were defined as expanded clones, among which the most frequent 10 clones in each sample were defined as the top 10 expanded clones. All unique clones were defined as unexpanded clones. 
Aged Treg accumulation \& late-onset EAE

\section{Luxol Fast Blue staining for demyelination assay of spinal cords}

537 Paraffin sections of the spinal cord (Fig. 6D) were stained with $0.1 \%$ Luxol Fast Blue 538 (LFB) solution (Sigma-Aldrich, Cat\#S3382) per a previous publication ${ }^{85}$, with a 539 modification adding eosin counterstaining (details in Supplemental Method-B).

540

\section{Statistics}

544 for multiple groups. Data from EAE scoring were analyzed by Mann-Whitney $U$ test to 545 compare between two groups, and Kruskal-Wallis test was used to compare multiple 546 groups followed by Dunnett's multiple comparisons post hoc test for pairwise comparisons 547 of groups. Body weight changes along with time between two groups were analyzed with 548 two-way repeated-measures ANOVA with Geisser-Greenhouse correction. Results were 549 considered statistically significant at values of * $p<0.05$; ** $p<0.01$; *** $p<0.001$; **** $550 p<0.0001$.

\section{Data Availability}

553

554

All scRNA-seq raw data are available on the Gene Expression omnibus (GEO)

555 (GSE182747) [https://www.ncbi.nlm.nih.gov/geo/query/acc.cgi?acc=GSE182747]. All individual numerical values, detailed statistic information and other regarding source data 


\section{Acknowledgements}

559 We thank Drs. Rance Berg and Sterling Ortega (UNTHSC) for critiques of experiments 560 and discussion, Dr. Nicky Hales (previously UNTHSC, current affiliation: 10x Genomics)

561 for performing single cell immune profiling, and the National Institutes of Health Tetramer

562 Core Facility at Emory University for providing the tetramer reagent.

563

564 Funding: Supported by NIH/NIAID grant R01AI121147 to D-M. S. and also partially 565 supported by NIH/NIA grant T32 AG020494 to W.W and R.T.

\section{Declaration of interests}

568 The authors declare no competing interests.

569

570

\section{Author contribution:}

572

W.W. performed most of the experiments and hands-on animal work, as well as wrote the manuscript; R.T. assisted with cell sorting experiments and edited the manuscript; J.O. performed some experiments; D-M.S. conceived and designed project, did some hands-on 
Aged Treg accumulation \& late-onset EAE

576

577

578

579

580

581

582

583

584

585

586

587

588

589

590

591

592

593

594

595

596

597

598

599

600

601

602

603

604

605

606

607

608

609

610

611

612

613

614

615

616

617

618

619

\section{References}

1. Coder B, Wang W, Wang L, Wu Z, Zhuge Q, Su DM. Friend or foe: the dichotomous impact of $\mathrm{T}$ cells on neuro-de/re-generation during aging. Oncotarget, (2016).

2. Liang $\mathrm{Z}$, et al. Impact of aging immune system on neurodegeneration and potential immunotherapies. Prog Neurobiol 157, 2-28 (2017).

3. McFarland HF, Martin R. Multiple sclerosis: a complicated picture of autoimmunity. Nat Immunol 8, 913-919 (2007).

4. Polliack ML, Barak Y, Achiron A. Late-onset multiple sclerosis. J Am Geriatr Soc 49, 168-171 (2001).

5. Sanai SA, et al. Aging and multiple sclerosis. Mult Scler 22, 717-725 (2016).

6. Wallack EM, Wiseman HD, Ploughman M. Healthy Aging from the Perspectives of 683 Older People with Multiple Sclerosis. Mult Scler Int 2016, 1845720 (2016).

7. Bermel RA, Rae-Grant AD, Fox RJ. Diagnosing multiple sclerosis at a later age: more than just progressive myelopathy. Mult Scler 16, 1335-1340 (2010).

8. Stern M, Sorkin L, Milton K, Sperber K. Aging with multiple sclerosis. Physical medicine and rehabilitation clinics of North America 21, 403-417 (2010).

9. Bolton C, Smith PA. The influence and impact of ageing and immunosenescence (ISC) on adaptive immunity during multiple sclerosis (MS) and the animal counterpart experimental autoimmune encephalomyelitis (EAE). Ageing Res Rev 41, 64-81 (2017).

10. Rist JM, Franklin RJ. Taking ageing into account in remyelination-based therapies for multiple sclerosis. J Neurol Sci 274, 64-67 (2008).

11. Bluestone JA, Bour-Jordan H, Cheng M, Anderson M. T cells in the control of organ-specific autoimmunity. J Clin Invest 125, 2250-2260 (2015).

12. Klein L, Robey EA, Hsieh CS. Central CD4(+) T cell tolerance: deletion versus regulatory T cell differentiation. Nat Rev Immunol 19, 7-18 (2019).

13. Palmer E. Negative selection--clearing out the bad apples from the T-cell repertoire. Nat Rev Immunol 3, 383-391 (2003). 
Aged Treg accumulation \& late-onset EAE

620 14. Klein L, Kyewski B, Allen PM, Hogquist KA. Positive and negative selection of

621

622

623

624

625

626

627

628

629

630

631

632

633

634

635

636

637

638

639

640

641

642

643

644

645

646

647

648

649

650

651

652

653

654

655

656

657

658

659

660

661

662

663

664 the T cell repertoire: what thymocytes see (and don't see). Nat Rev Immunol 14, 377-391 (2014).

15. Bluestone JA, Tang Q. How do CD4+CD25+ regulatory $\mathrm{T}$ cells control autoimmunity? Curr Opin Immunol 17, 638-642 (2005).

16. Dominguez-Villar M, Hafler DA. Regulatory T cells in autoimmune disease. Nat Immunol 19, 665-673 (2018).

17. Hsieh CS, Zheng Y, Liang Y, Fontenot JD, Rudensky AY. An intersection between the self-reactive regulatory and nonregulatory T cell receptor repertoires. Nat Immunol 7, 401-410 (2006).

18. Lee HM, Bautista JL, Scott-Browne J, Mohan JF, Hsieh CS. A broad range of selfreactivity drives thymic regulatory $\mathrm{T}$ cell selection to limit responses to self. Immunity 37, 475-486 (2012).

19. Hsieh CS, Lee HM, Lio CW. Selection of regulatory T cells in the thymus. Nat Rev Immunol 12, 157-167 (2012).

20. Callender LA, et al. Human CD8(+) EMRA T cells display a senescenceassociated secretory phenotype regulated by p38 MAPK. Aging Cell 17, (2018).

21. Coppe JP, et al. Senescence-associated secretory phenotypes reveal cellnonautonomous functions of oncogenic RAS and the p53 tumor suppressor. PLoS Biol 6, 2853-2868 (2008).

22. Coppe JP, Desprez PY, Krtolica A, Campisi J. The senescence-associated secretory phenotype: the dark side of tumor suppression. Annu Rev Pathol 5, 99-118 (2010).

23. Giunta S. Is inflammaging an auto[innate]immunity subclinical syndrome? Immun Ageing 3, 12 (2006).

24. Oh J, Wang W, Thomas R, Su DM. Capacity of tTreg generation is not impaired in the atrophied thymus. PLoS Biol 15, e2003352 (2017).

25. Raynor J, Lages CS, Shehata H, Hildeman DA, Chougnet CA. Homeostasis and function of regulatory T cells in aging. Curr Opin Immunol 24, 482-487 (2012).

26. Garg SK, et al. Aging is Associated with Increased Regulatory T-cell Function. Aging Cell 13, 441-448 (2014). 
Aged Treg accumulation \& late-onset EAE

665 27. Lages CS, et al. Functional regulatory $\mathrm{T}$ cells accumulate in aged hosts and

666

667

668

669

670

671

672

673

674

675

676

677

678

679

680

681

682

683

684

685

686

687

688

689

690

691

692

693

694

695

696

697

698

699

700

701

702

703

704

705

706

707

708

709

710 promote chronic infectious disease reactivation. J Immunol 181, 1835-1848 (2008).

28. Liu F, et al. CD8(+) cytotoxic T cell and FOXP3(+) regulatory T cell infiltration in relation to breast cancer survival and molecular subtypes. Breast Cancer Res Treat 130, 645-655 (2011).

29. Curiel TJ. Regulatory T cells and treatment of cancer. Curr Opin Immunol 20, 241-246 (2008).

30. Takeuchi Y, Nishikawa H. Roles of regulatory T cells in cancer immunity. Int Immunol 28, 401-409 (2016).

31. Casares N, et al. A peptide inhibitor of FOXP3 impairs regulatory T cell activity and improves vaccine efficacy in mice. J Immunol 185, 5150-5159 (2010).

32. Rosenkranz D, et al. Higher frequency of regulatory T cells in the elderly and increased suppressive activity in neurodegeneration. J Neuroimmunol 188, 117-127 (2007).

33. Kleinewietfeld $M$, Hafler DA. Regulatory $T$ cells in autoimmune neuroinflammation. Immunol Rev 259, 231-244 (2014).

34. Buc M. Role of regulatory $\mathrm{T}$ cells in pathogenesis and biological therapy of multiple sclerosis. Mediators Inflamm 2013, 963748 (2013).

35. Furtado GC, Olivares-Villagomez D, Curotto de Lafaille MA, Wensky AK, Latkowski JA, Lafaille JJ. Regulatory $\mathrm{T}$ cells in spontaneous autoimmune encephalomyelitis. Immunol Rev 182, 122-134 (2001).

36. Minden SL, Frankel D, Hadden LS, Srinath KP, Perloff JN. Disability in elderly people with multiple sclerosis: An analysis of baseline data from the Sonya Slifka Longitudinal Multiple Sclerosis Study. NeuroRehabilitation 19, 55-67 (2004).

37. Thomas R, Wang W, Su DM. Contributions of Age-Related Thymic Involution to Immunosenescence and Inflammaging. Immun Ageing 17, 2 (2020).

38. Kleinewietfeld M, Hafler DA. The plasticity of human Treg and Th17 cells and its role in autoimmunity. Semin Immunol 25, 305-312 (2013).

39. Miller SD, Karpus WJ. Experimental autoimmune encephalomyelitis in the mouse. Current protocols in immunology / edited by John E Coligan [et al] Chapter 15, Unit 1511 (2007). 
711

712

713

714

715

716

717

718

719

720

721

722

723

724

725

726

727

728

729

730

731

732

733

734

735

736

737

738

739

740

741

742

743

744

745

746

747

748

749

750

751

752

753

754

755

756

40. Bittner S, Afzali AM, Wiendl H, Meuth SG. Myelin oligodendrocyte glycoprotein (MOG35-55) induced experimental autoimmune encephalomyelitis (EAE) in C57BL/6 mice. J Vis Exp, (2014).

41. Lowther DE, Hafler DA. Regulatory $\mathrm{T}$ cells in the central nervous system. Immunol Rev 248, 156-169 (2012).

42. Huseby ES, Liggitt D, Brabb T, Schnabel B, Ohlen C, Goverman J. A pathogenic role for myelin-specific CD8(+) T cells in a model for multiple sclerosis. J Exp Med 194, 669-676 (2001).

43. Liu Y, Teige I, Birnir B, Issazadeh-Navikas S. Neuron-mediated generation of regulatory T cells from encephalitogenic T cells suppresses EAE. Nat Med 12, 518-525 (2006).

44. Hong J, Zang YC, Nie H, Zhang JZ. CD4+ regulatory T cell responses induced by T cell vaccination in patients with multiple sclerosis. Proc Natl Acad Sci U S A 103, 5024-5029 (2006).

45. Buckner JH. Mechanisms of impaired regulation by CD4(+)CD25(+)FOXP3(+) regulatory T cells in human autoimmune diseases. Nat Rev Immunol 10, 849859 (2010).

46. Randolph DA, Fathman CG. Cd4+Cd25+ regulatory $\mathrm{T}$ cells and their therapeutic potential. Annual review of medicine 57, 381-402 (2006).

47. Tsukamoto $\mathrm{H}$, et al. Age-associated increase in lifespan of naive CD4 T cells contributes to T-cell homeostasis but facilitates development of functional defects. Proc Natl Acad Sci U S A 106, 18333-18338 (2009).

48. Tsukamoto H, Huston GE, Dibble J, Duso DK, Swain SL. Bim dictates naive CD4 $\mathrm{T}$ cell lifespan and the development of age-associated functional defects. $J$ Immunol 185, 4535-4544 (2010).

49. Chougnet CA, et al. A major role for Bim in regulatory T cell homeostasis. $J$ Immunol 186, 156-163 (2011).

50. Sawant DV, Vignali DA. Once a Treg, always a Treg? Immunol Rev 259, 173-191 (2014).

51. Rubtsov YP, et al. Stability of the regulatory T cell lineage in vivo. Science 329, 1667-1671 (2010).

52. Bailey-Bucktrout SL, et al. Self-antigen-driven activation induces instability of regulatory $\mathrm{T}$ cells during an inflammatory autoimmune response. Immunity 39, 949-962 (2013). 
Aged Treg accumulation \& late-onset EAE

757

758

759

760

761

762

763

764

765

766

767

768

769

770

771

772

773

774

775

776

777

778

779

780

781

782

783

784

785

786

787

788

789

790

791

792

793

794

795

796

797

798

799

800

801

802

53. McClymont SA, et al. Plasticity of human regulatory T cells in healthy subjects and patients with type 1 diabetes. J Immunol 186, 3918-3926 (2011).

54. Kitz A, Dominguez-Villar M. Molecular mechanisms underlying Th1-like Treg generation and function. Cell Mol Life Sci 74, 4059-4075 (2017).

55. Martinez-Jimenez CP, et al. Aging increases cell-to-cell transcriptional variability upon immune stimulation. Science 355, 1433-1436 (2017).

56. Dulken BW, et al. Single-cell analysis reveals $\mathrm{T}$ cell infiltration in old neurogenic niches. Nature 571, 205-210 (2019).

57. Saxena A, Desbois S, Carrie N, Lawand M, Mars LT, Liblau RS. Tc17 CD8+ T cells potentiate Th1-mediated autoimmune diabetes in a mouse model. J Immunol 189, 3140-3149 (2012).

58. Huber M, et al. IL-17A secretion by CD8+ T cells supports Th17-mediated autoimmune encephalomyelitis. J Clin Invest 123, 247-260 (2013).

59. Walker LS, Chodos A, Eggena M, Dooms H, Abbas AK. Antigen-dependent proliferation of CD4+CD25+ regulatory T cells in vivo. J Exp Med 198, 249-258 (2003).

60. Attridge K, Walker LS. Homeostasis and function of regulatory T cells (Tregs) in vivo: lessons from TCR-transgenic Tregs. Immunol Rev 259, 23-39 (2014).

61. Baruch $\mathrm{K}$, et al. Breaking immune tolerance by targeting Foxp3(+) regulatory T cells mitigates Alzheimer's disease pathology. Nature communications 6, 7967 (2015).

62. Liu Y, et al. Inhibition of p300 impairs Foxp3(+) T regulatory cell function and promotes antitumor immunity. Nat Med 19, 1173-1177 (2013).

63. Kim JM, Rasmussen JP, Rudensky AY. Regulatory T cells prevent catastrophic autoimmunity throughout the lifespan of mice. Nat Immunol 8, 191-197 (2007).

64. Raposo C, et al. CNS repair requires both effector and regulatory $\mathrm{T}$ cells with distinct temporal and spatial profiles. J Neurosci 34, 10141-10155 (2014).

65. Awad A, Stuve O. Multiple sclerosis in the elderly patient. Drugs Aging 27, 283294 (2010).

66. Ji Q, Goverman J. Experimental autoimmune encephalomyelitis mediated by CD8+ T cells. Ann N Y Acad Sci 1103, 157-166 (2007). 
Aged Treg accumulation \& late-onset EAE

803

804

805

806

807

808

809

810

811

812

813

814

815

816

817

818

819

820

821

822

823

824

825

826

827

828

829

830

831

832

833

834

835

836

837

838

839

840

841

842

843

844

845

846

847

67. Crawford MP, et al. High prevalence of autoreactive, neuroantigen-specific CD8+ T cells in multiple sclerosis revealed by novel flow cytometric assay. Blood 103, 4222-4231 (2004).

68. Kohm AP, Carpentier PA, Anger HA, Miller SD. Cutting edge: CD4+CD25+ regulatory $\mathrm{T}$ cells suppress antigen-specific autoreactive immune responses and central nervous system inflammation during active experimental autoimmune encephalomyelitis. J Immunol 169, 4712-4716 (2002).

69. Reddy J, et al. Myelin proteolipid protein-specific CD4+CD25+ regulatory cells mediate genetic resistance to experimental autoimmune encephalomyelitis. Proc Natl Acad Sci U S A 101, 15434-15439 (2004).

70. Saresella M, et al. PD1 negative and PD1 positive CD4+ T regulatory cells in mild cognitive impairment and Alzheimer's disease. Journal of Alzheimer's disease : JAD 21, 927-938 (2010).

71. Liu Y, et al. FoxA1 directs the lineage and immunosuppressive properties of a novel regulatory T cell population in EAE and MS. Nat Med 20, 272-282 (2014).

72. Zhou $\mathrm{X}$, et al. Instability of the transcription factor Foxp3 leads to the generation of pathogenic memory T cells in vivo. Nat Immunol 10, 1000-1007 (2009).

73. Tan TG, Mathis D, Benoist C. Singular role for T-BET+CXCR3+ regulatory T cells in protection from autoimmune diabetes. Proc Natl Acad Sci U S A 113, 1410314108 (2016).

74. Korn T, et al. Myelin-specific regulatory T cells accumulate in the CNS but fail to control autoimmune inflammation. Nat Med 13, 423-431 (2007).

75. Kitz A, de Marcken M, Gautron AS, Mitrovic M, Hafler DA, Dominguez-Villar M. AKT isoforms modulate Th1-like Treg generation and function in human autoimmune disease. EMBO Rep 17, 1169-1183 (2016).

76. Deczkowska A, Baruch K, Schwartz M. Type I/II Interferon Balance in the Regulation of Brain Physiology and Pathology. Trends Immunol 37, 181-192 (2016).

77. Kunis G, et al. IFN-gamma-dependent activation of the brain's choroid plexus for CNS immune surveillance and repair. Brain 136, 3427-3440 (2013).

78. Kunis G, Baruch K, Miller O, Schwartz M. Immunization with a Myelin-Derived Antigen Activates the Brain's Choroid Plexus for Recruitment of 
Aged Treg accumulation \& late-onset EAE

848

849

850

851

852

853

854

855

856

857

858

859

860

861

862

863

864

865

866

867

868

869

870

871

872

873

874

875

876

877

878

879

880

881

882

883

884
Immunoregulatory Cells to the CNS and Attenuates Disease Progression in a Mouse Model of ALS. J Neurosci 35, 6381-6393 (2015).

79. Mars LT, Saikali P, Liblau RS, Arbour N. Contribution of CD8 T lymphocytes to the immuno-pathogenesis of multiple sclerosis and its animal models. Biochim Biophys Acta 1812, 151-161 (2011).

80. Mockus TE, Munie A, Atkinson JR, Segal BM. Encephalitogenic and Regulatory CD8 T Cells in Multiple Sclerosis and Its Animal Models. J Immunol 206, 3-10 (2021).

81. Wagner CA, Roque PJ, Mileur TR, Liggitt D, Goverman JM. Myelin-specific CD8+ T cells exacerbate brain inflammation in CNS autoimmunity. J Clin Invest 130, 203-213 (2020).

82. Baughman EJ, et al. Neuroantigen-specific CD8+ regulatory T-cell function is deficient during acute exacerbation of multiple sclerosis. J Autoimmun 36, 115-124 (2011).

83. Sinha S, Itani FR, Karandikar NJ. Immune regulation of multiple sclerosis by CD8+ T cells. Immunol Res 59, 254-265 (2014).

84. Niederlova V, Tsyklauri O, Chadimova T, Stepanek O. CD8(+) Tregs revisited: A heterogeneous population with different phenotypes and properties. Eur J Immunol 51, 512-530 (2021).

85. Wang W, et al. Extracellular vesicles extracted from young donor serum attenuate inflammaging via partially rejuvenating aged T-cell immunotolerance. FASEB journal : official publication of the Federation of American Societies for Experimental Biology, fj201800059R (2018).

86. Yoo IH, Kim MJ, Kim J, Sung JJ, Park ST, Ahn SW. The Anti-Inflammatory Effect of Sulforaphane in Mice with Experimental Autoimmune Encephalomyelitis. J Korean Med Sci 34, e197 (2019). 
Aged Treg accumulation \& late-onset EAE

885

886

887

888

889

890

891

892

893

894

895

896

897

898

899

900

901

902

903

904

905

906

907

908

909

910

911

912

913

914

915

916

917

918

919

920

921

922

923

924

925

926

927

928

929

\section{Figure Legends:}

Figure 1. Characteristics of EAE disease in young versus aged mice. (A) Workflow for immunization and induction of EAE in C57BL/6 mice with reduced dose $(80 \mu \mathrm{g} / 10 \mathrm{~g}$ body weight) of MOG peptide and follow-up analysis. (B) The variability of EAE pathological scores (left panel) and body weights during disease onset (right panel) in aged male and female mice. (C) Characteristics of EAE pathological scores (left panel) and body weights during disease onset (right panel) in young (cherry-color line) versus aged (blue line) female mice. The $p$-values of EAE scores were calculated by Mann-Whitney $U$ test and body weight changes were calculated by two-way repeated-measures ANOVA with Geisser-Greenhouse correction, and a statistically significant difference was considered to be $p<0.05$.

Figure 2. Imbalanced distributions of pan- and MOG-specific Treg cells in the periphery of late-onset EAE disease of aged mice. Mice were immunized as Fig. 1A workflow. Then, T cells in LNs and spleen were analyzed. (A) Flow cytometry gating strategies show pan (poly-clonal)- and MOG-specific Treg cells in LNs and spleens of young and aged mice. MOG-specific gate was determined by a dot-plot of MHC-II MOGspecific I-A ${ }^{\mathrm{b}}$ tetramer versus MHC-II control tetramer I-A ${ }^{\mathrm{b}}$. (B) Summarized results of the percentages of pan- (striped bars) and MOG-specific (open bars) Treg cells (left panel) and Teff cells (middle panel), and ratios of Treg/Teff cells (right panel) in LNs and spleen between young (cherry) and aged (blue) mice. (C) Flow cytometry gating strategies show $\mathrm{FoxP}^{+}$peaks (bottom panel) from $\mathrm{CD} 4{ }^{+} \mathrm{CD} 25^{+}$gates of young (top panel) and aged (middle panel) mice. (D) Summarized results of the relative quantitative (RQ) mean fluorescent intensity (MFI) of FoxP3 expression in pan- (striped bars) and MOG-specific (open bars) $\mathrm{CD}^{+} \mathrm{CD} 25^{+}$population in LNs and spleen between young (cherry) and aged (blue) mice. In panels B and D, each symbol represents an individual animal sample. The $p$-values between two groups were analyzed by unpaired Student's t-test, and a statistically significant difference was considered to be $p<0.05$. "N.S." stands for "not significant", and error bars indicate mean \pm SEM.

Figure 3. Imbalanced distributions of pan- and MOG-specific Treg in the CNS of lateonset EAE disease of aged mice. Mice were immunized per Fig. 1A workflow. Then, T cells in the CNS were isolated via gradient centrifuge and analyzed by flow cytometry. (A) Gating strategies show pan-Treg population (left two columns) and MOG-specific Treg population (right two columns) in the CNS. (B) Summarized results of the percentages of pan- (striped bars) and MOG-specific (open bars) Treg cells (top panel) and Teff cells (middle panel), and ratios of Treg/Teff cells (bottom panel) in the CNS (brain and spinal cord) between young (cherry) and aged (blue) mice. (C) Flow cytometry gating strategies show FoxP $3^{+}$peaks (bottom panels) from $\mathrm{CD}^{+} \mathrm{CD} 25^{+}$gates of the $\mathrm{CNS}$ (brain and spinal cord) of young (top panel) and aged (middle panel) mice. (D) Summarized results of the relative quantitative (RQ) mean fluorescence intensity (MFI) of FoxP3 expression in pan(striped bars) and MOG-specific (open bars) $\mathrm{CD} 4{ }^{+} \mathrm{CD} 25^{+}$populations in the brain and spinal cord between young (cherry) and aged (blue) mice. In panels B and D, each symbol represents an individual animal sample. The $p$-values between two groups were analyzed 
Aged Treg accumulation \& late-onset EAE

by unpaired Student's t-test, and a statistically significant difference was considered to be $p<0.05$, "N.S." stands for "not significant", and error bars indicate mean \pm SEM.

\begin{abstract}
Figure 4. Treg function-associated profile analysis of altered Treg plasticity and proinflammatory CD8 $\mathrm{T}$ cells in the CNS of aged mice during late-onset EAE. Mice were immunized per Fig. 1A workflow. (A) Workflow of sc-RNA-seq for CNS infiltrated T cells. T cells in the CNS (brain and spinal cord) were isolated via gradient centrifugation and sorted for $\mathrm{CD} 3{ }^{+} \mathrm{CD} 11 \mathrm{~b}^{\text {-neg }}$ cells by flow cytometry 30 days after immunization. Then, single cells were captured and emulsified with specific gel beads for reverse transcription and construction of cDNA library for high-throughput sequencing. (B) The pattern of young (left panel) and aged (right panel) T cells from the CNS of three young and three aged EAE mice with t-distributed stochastic neighbor embedding (t-SNE) plots. (C) Expressions (Unique Molecular Identifier, UMI) of ifng (left panel) and il17a (right panel) genes in single Treg $\left(\mathrm{CD}^{+} \mathrm{FoxP}^{+}\right)$cells of the young (cherry) and aged (blue) CNS. (D) Expressions of ifng gene (left panel) and $i l 17 a$ (right panel) in single CD8 ${ }^{+} \mathrm{T}$ cells of the young (cherry) and aged (blue) CNS. Data in panels C and D were analyzed by unpaired Student's t-test, and a statistically significant difference was considered to be $p<0.05$. Each symbol represents a single cell.
\end{abstract}

Figure 5. Clonal expansion in CNS-infiltrated $\mathrm{CD4}^{+} \mathrm{T}$ populations of young and aged mice during EAE. Based on TCR $\alpha \beta$ sequence similarity from single-cell immune profile RNA-Seq analysis, CNS-infiltrated Teff and Treg cells were divided into expanded T clones (more than one similar TCR sequences) and unexpanded T clones (unique TCR sequence, with clone size $=1$ ). In the expanded $\mathrm{T}$ clones, we further divided them into Group-A: top 10 clones (with most similar TCR sequences) and Group-B: other expanded clones (all other $\geq 2$ similar TCR sequences). (A) Pie charts show expanded clones (Groups-A and -B) and unexpanded clones (Group-C) of Teff (top two pies) and Treg (bottom two pies) cells in total $\mathrm{CD} 4^{+} \mathrm{T}$ cells from young (left two pies) and aged (right two pies) CNS during EAE. (B) Summarized results of the frequencies of all expanded clones of Teff (left panel) and Treg (right panel) cells in total $\mathrm{CD}^{+} \mathrm{T}$ cells from young (cherry open bars) and aged (blue open bars) CNS during EAE. Each symbol represents one mouse. Data were analyzed by unpaired Student's t-test, and a statistically significant difference was considered to be $p<0.05$.

Figure 6. Alleviation of EAE severity after transient inhibition of FoxP3 expression in the accumulated pTreg cells in late-onset EAE in aged mice. (A) Workflow of EAE induction, transient inhibition of pTreg cells, blood collection time-points (red arrowheads) for Treg cell tests, and demyelination assay. (B) Effects of transient inhibition of pTreg cells in aged mice. At the first evaluation (one day before the first injection of P300i or vehicle), the percentages of pTreg cells in the two aged groups were higher than the young (left panel). At the second evaluation (one day after the last injection of P300i or vehicle), the percentages of pTreg cells and expression (MFI) of FoxP3 in the aged group treated with P300i (black triangles/line) were significantly reduced. At the third evaluation (12 days after the last treatment), the pTreg cells in the P300i-treated aged group were restored 
Aged Treg accumulation \& late-onset EAE

974 to the same levels as the vehicle-treated control aged group (blue dots/line). All data are

975 expressed as mean \pm SEM and were analyzed by One-way ANOVA followed by Dunnett's 976 multiple post-hoc test. ${ }^{*} p<0.05$ young mice +vehicle v.s. aged mice +vehicle; $* * p<0.01$ 977 young mice +vehicle v.s. aged mice +vehicle; $* * * * p<0.0001$, young mice +vehicle v.s. 978 aged mice +vehicle; \#\# $p<0.01$, aged mice + vehicle v.s. aged mice + P300i; \#\#\#\# $p<$ 0.0001, aged mice + vehicle v.s. aged mice + P300i. Animal numbers in each group are

980 listed in each panel. (C) Alleviation of the symptoms in late-onset EAE of aged mice. The 981 EAE scores of 5x P300i-treated aged group (black triangles/line) were significantly

982

983 reduced compared to their counterparts, the vehicle-treated control aged group (blue dots/line). The $p$-values were calculated using Kruskal-Wallis test followed by Dunnett's

984

985 multiple comparisons post hoc test for pairwise comparisons of groups. (D) Illustration of

986

987

988 a mouse brain and spinal cord indicating the thoracic segment of the spinal cord for LFBeosin staining (rightmost illustration). Three representative spinal cord section images of LFB-eosin staining, showing alleviation of demyelination in the spinal cords of aged mice treated with 5x P300i (right image), compared to their counterparts, the vehicle-treated age-matched control mice (middle image). The dotted outlines indicate areas of large foci of demyelination, and blue arrow heads show small foci of demyelination. This experiment was repeated three times with three mice in each group with essentially identical results.

992

993

Figure 7. Transient inhibition of accumulated pan-pTreg cells induced the alleviation

994 of late-onset EAE in aged mice, potentially due to restored immune cell trafficking.

995

996 The workflow of the pTreg inhibition is shown in Fig. 6A. (A) Expression of IFN- $\gamma^{+}$in CP-

997 residing $\mathrm{CD} 5^{+}$cells were analyzed one day after the last P300i treatment (Fig. 6A, the second test red arrow). A representative histogram shows IFN $-\gamma^{+} \mathrm{CD} 45^{+}$cells residing at the $\mathrm{CP}$ isolated from the brains of young and aged mice treated with P300i or vehicle. Percentages of IFN- $\gamma^{+}$cells in $\mathrm{CD}^{+} 5^{+}$cells and MFI of IFN- $\gamma$ expression are listed in the table (right). (B) Flow cytometry gating strategies of pan-Treg and MOG-specific Treg cells, similar to Fig. 3A, in the CNSs of young and aged mice with P300i- or vehicletreatment. (C) Summarized results of the percentages of pan- (striped bars) and MOGspecific (opened bars) Treg cells (left panel) and Teff cells (middle panel), and ratios of Treg/Teff cells (right panel) in the CNS (a combination of the brain and the spinal cord) among young (cherry) and aged mice, treated with vehicle (blue) or with P300i (black). (D) Flow cytometry gating strategies show representative $\mathrm{FoxP}^{+}$gates (bottom panels) from $\mathrm{CD} 4{ }^{+} \mathrm{CD} 25^{+}$gates of the CNS (brain and spinal cord) of the three groups of mice. (E) Summarized results of the RQ-MFI of FoxP3 expression in pan- (striped bars) and MOGspecific (open bars) $\mathrm{CD} 4{ }^{+} \mathrm{CD} 25^{+}$population in the CNS among young (cherry) and aged mice treated with vehicle (blue) or P300i (black). In panels $\mathrm{C}$ and $\mathrm{E}$, each symbol represents an individual animal sample. Data are expressed as mean \pm SEM. The $p$-values between three groups were analyzed by one-way ANOVA with a Dunnett's multiple post-hoc test, and a statistically significant difference was considered to be $p<0.05$, "N.S." stands for "not significant".

1015 
Aged Treg accumulation \& late-onset EAE

1016

1017

1018

1019

1020

1021

1022

1023

1024

1025

1026

1027

1028

1029

1030

1031

1032

1033

1034

1035

1036

1037

1038

1039

1040

1041

1042

1043

1044

1045

1046

1047

1048

1049

1050

1051

1052

1053

1054

1055

1056

1057

1058

1059

1060

1061

Supplemental Figure S1. Two types of EAE scores of aged female mice with equal dosage of MOG35-55 peptide as young mice. (A) Workflow for immunization and

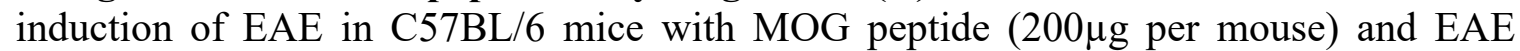
disease course observation. (B) Type-I EAE disease course in aged female mice with young female mice as control. (C) Type-II EAE disease course in aged female mice with young female mice as control. The p-values of EAE scores were calculated by Mann-Whitney U test and a statistically significant difference was considered to be $p<0.05$.

Supplemental Figure $\mathbf{S 2}$. Flow cytometric gating strategies of $\mathbf{T}$ cell populations in the periphery and the CNS. (A) representative gating strategy for the T cell populations in the periphery (spleen/lymph node). (B) representative gating strategy for the $\mathrm{T}$ cell populations in the CNS (brain/spinal cord).

Supplemental Figure S3. Balanced pan- and MOG-specific Treg distributions in the CNS of late-onset EAE disease (8 days after immunization with MOG) in aged mice. (A) Flow cytometry gating strategies show pan-Treg population (left two columns) and MOG-specific Treg population (right two columns) in the CNS. (B) Summarized results of the percentages of pan- (striped bars) and MOG-specific (open bars) Treg cells (top panel) and Teff cells (middle panel), and ratios of Treg/Teff cells (bottom panel) in the CNS (brain and spinal cord) between young (cherry) and aged (blue) mice. (C) Flow cytometry gating strategies show representative FoxP3+ gates (bottom panels) from $\mathrm{CD} 4^{+} \mathrm{CD} 25^{+}$gates of the CNS (mix of brain and spinal cord) of young and aged mice. (D) Summarized results of the RQ-MFI of FoxP3 expression in pan- (striped bars) and MOGspecific (open bars) $\mathrm{CD}^{+} \mathrm{CD} 25^{+}$population in the CNS between young (cherry) and aged (blue) mice. In panels B and D, each symbol represents an individual animal sample. The statistical significance between the two groups was analyzed by unpaired Student's $t$-test, "N.S." stands for "not significant", and error bars indicate mean \pm SEM.

Supplemental Figure. S4. Clonal expansion in CNS-infiltrated CD4+ T populations of individual young and aged mice during EAE. Leftmost column: individual pie charts of young Teff cell clonal expansion; second left column: individual pie charts of aged Teff cell clonal expansion; second right column: individual pie charts of young Treg cell clonal expansion; rightmost column: individual pie charts of aged Treg cell clonal expansion.

Supplemental Figure S5. Gating strategies of peripheral blood Treg cell dynamics during partial and transient pTreg cell inhibition. (A) Flow cytometry gating strategies show the frequencies of peripheral blood Treg cells in the three groups of mice 11-DPI (one day before $\mathrm{p} 300 \mathrm{i}$ or vehicle treatment), 17-DPI (one day after the last $\mathrm{p} 300 \mathrm{i}$ or vehicle treatment) and 28-DPI (12 days after the last p300i or vehicle treatment). (B) Flow cytometry gating strategies show representative FoxP3+ gates (bottom panels) from $\mathrm{CD}^{+} \mathrm{CD} 25^{+}$gates of the peripheral blood Treg cells in the three groups of mice 11-DPI, 17-DPI, and 28-DPI.

Supplemental Figure. S6. Alleviation of EAE severity after transient depletion of accumulated pTreg cells in late-onset EAE in aged Foxp3-DTR mice. (A) Flow cytometry gating strategies show the frequencies of peripheral blood Treg cells in the three 
Aged Treg accumulation \& late-onset EAE

1062 groups of mice 11-DPI (one day before DT or vehicle treatment), 13-DPI (one day after 1063 DT or vehicle treatment) and 28-DPI (16 days after DT or vehicle treatment). (B) 1064 Summarized results of dynamic changes of Treg frequencies in the peripheral blood of 1065 three groups of mice. All data are expressed as mean \pm SEM and are analyzed by One-way 1066 ANOVA followed by Dunnett's multiple post-hoc test. $* * * p<0.001$, young-DTR mice + 1067 vehicle v.s. Aged-DTR mice + vehicle; $* * * * p<0.0001$, young-DTR mice +vehicle v.s. 1068 Aged-DTR mice +vehicle; \#\#\#\# $p<0.0001$, aged-DTR mice + vehicle v.s. aged-DTR mice $1069+$ DT. Animal numbers in each group are listed in each panel. (C) Alleviation of the 1070 symptoms in late-onset EAE of aged-DTR mice. The $p$-values were calculated with 1071 Kruskal-Wallis test followed by Dunnett's multiple comparisons post hoc test for pairwise 1072 comparisons of groups, with $\mathrm{p}<0.05$ as statistically significant. (D) Flow cytometry pan1073 Treg and MOG-specific Treg cells in the CNS of young-DTR and aged-DTR mice with 1074 DT or vehicle treatment. 
bioRxiv preprint doi: https://doi.org/10.1101/2021.12.16.472986; this version posted December 17, 2021. The copyright holder for this preprint (which was not certified by peer review) is the author/funder. All rights reserved. No reuse allowed without permission.

A.

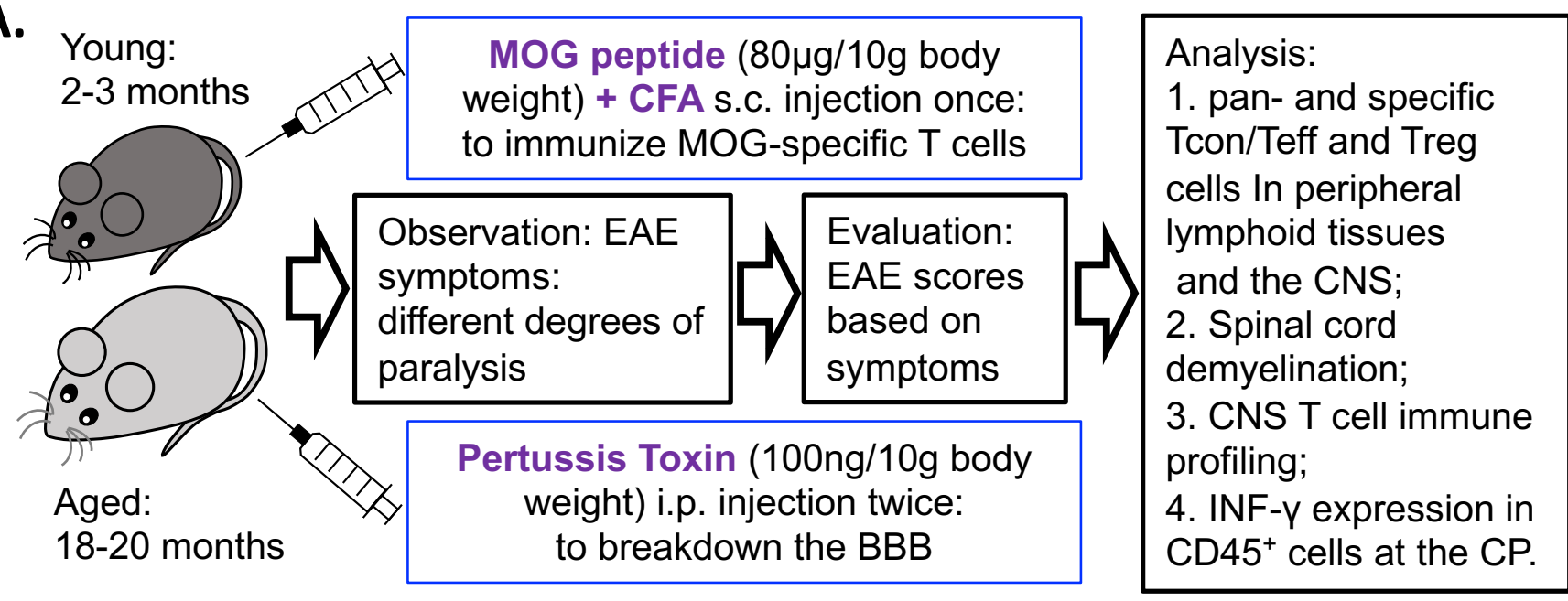

B.
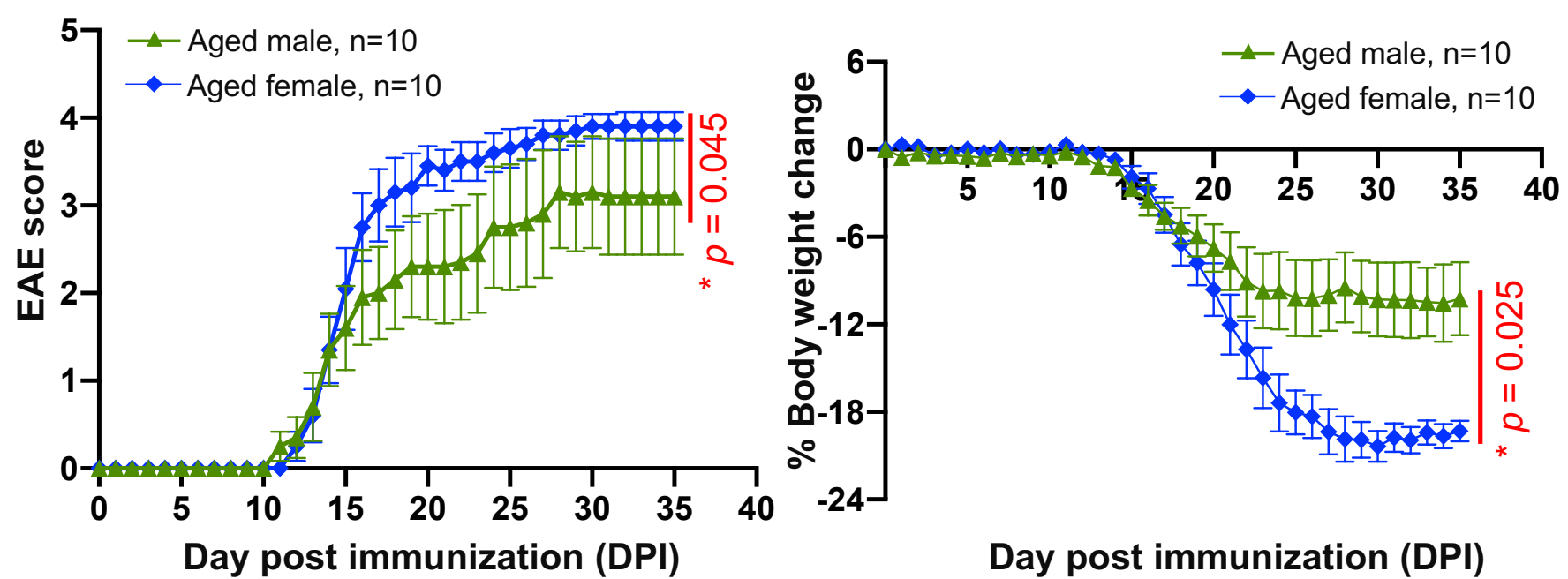

Day post immunization (DPI)
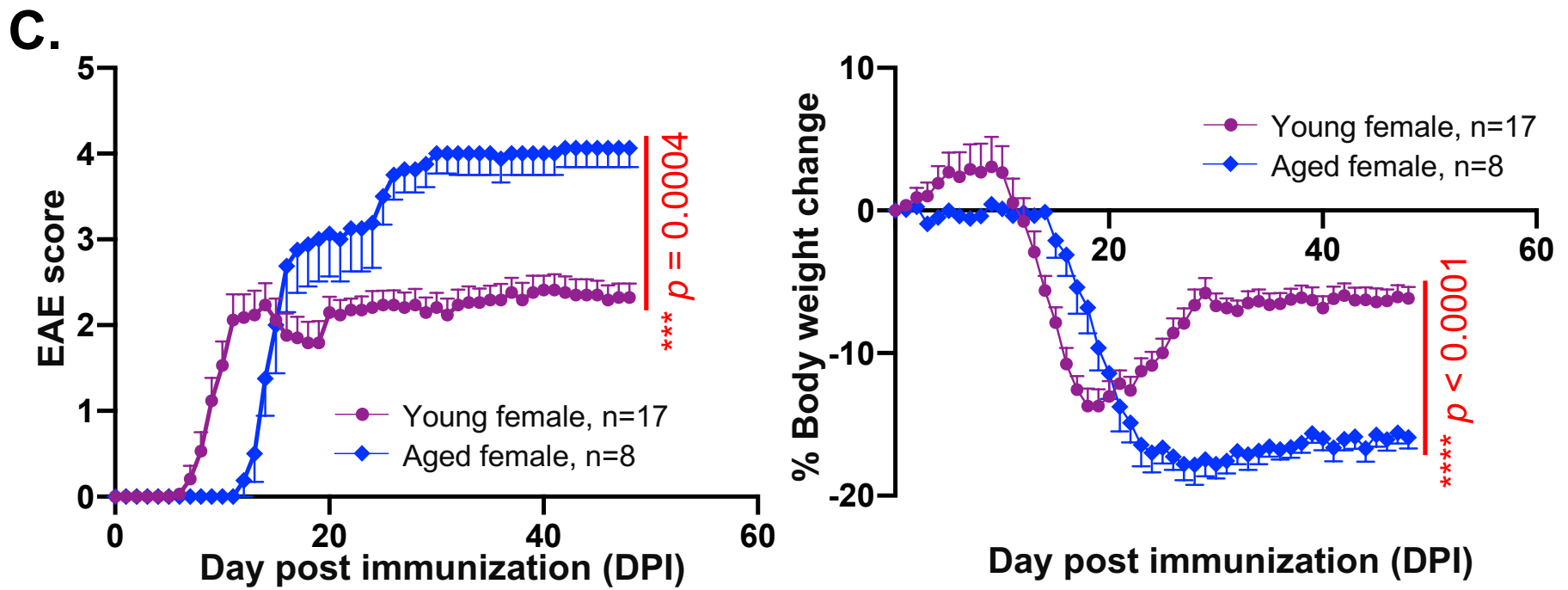

Day post immunization (DPI)

Fig. 1. Characteristics of EAE disease in young versus aged mice 
A.

LN

Spleen

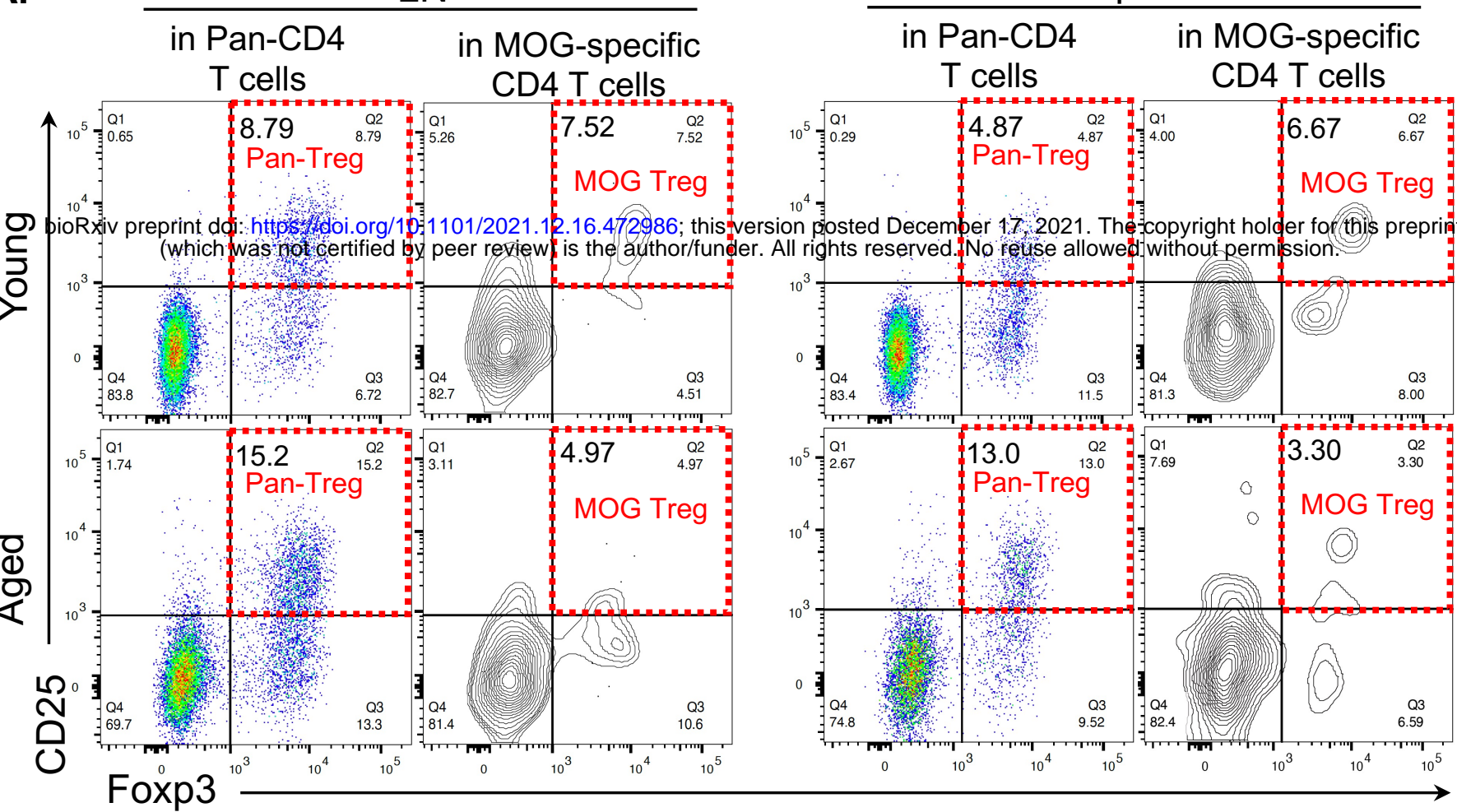

B.

एum Young Pan $\quad$ Vma Aged Pan $\square$ Young MOG-specific $\square$ Aged MOG-specific

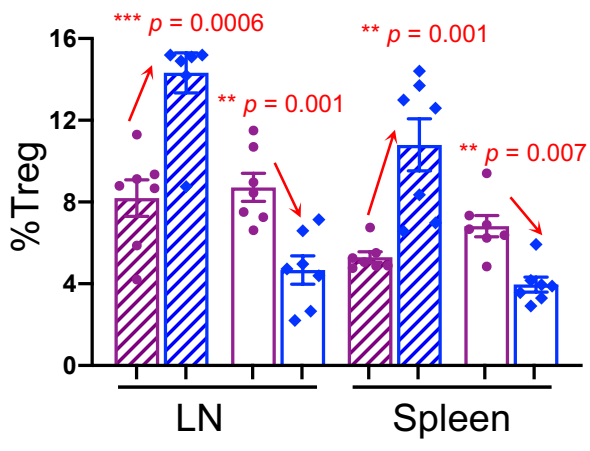

C.
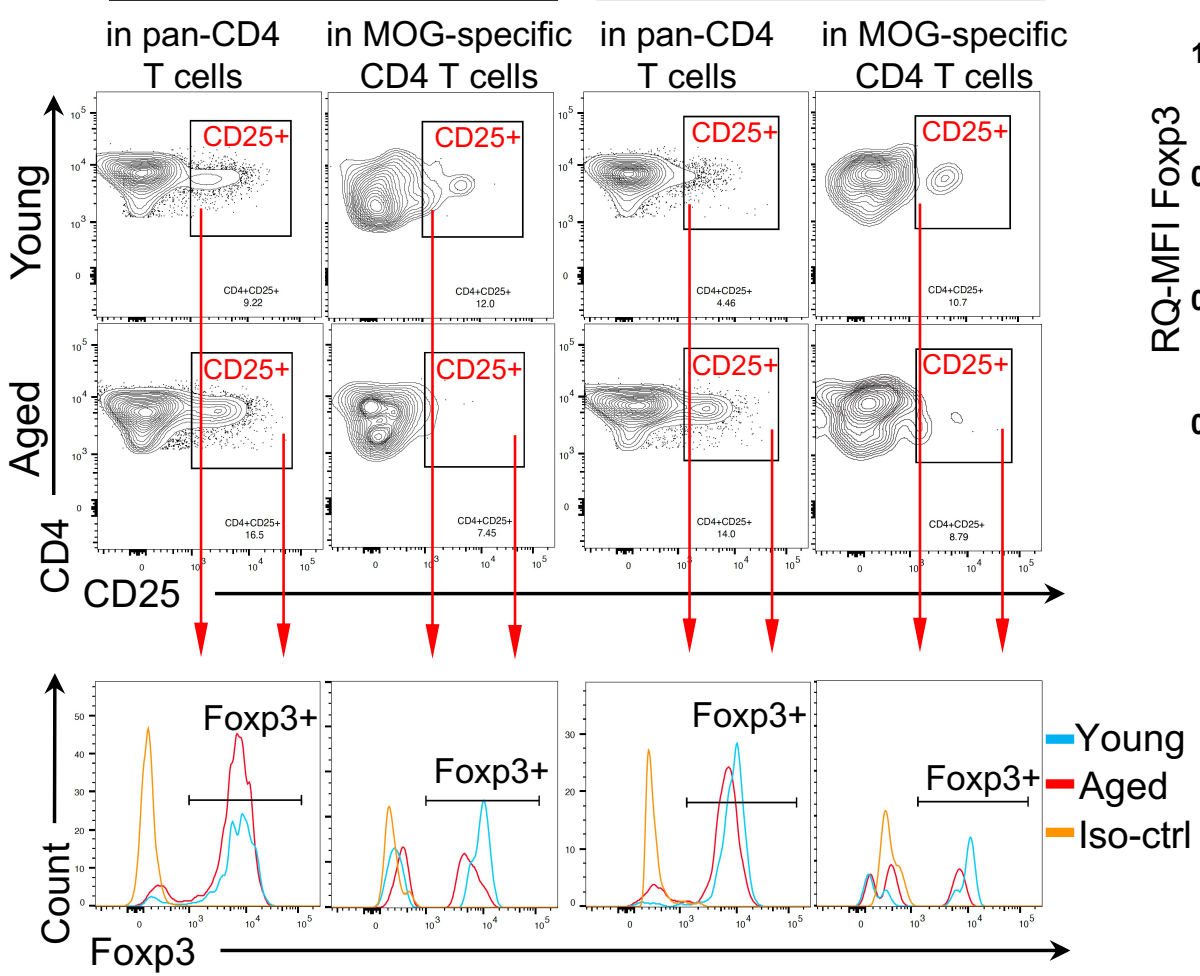

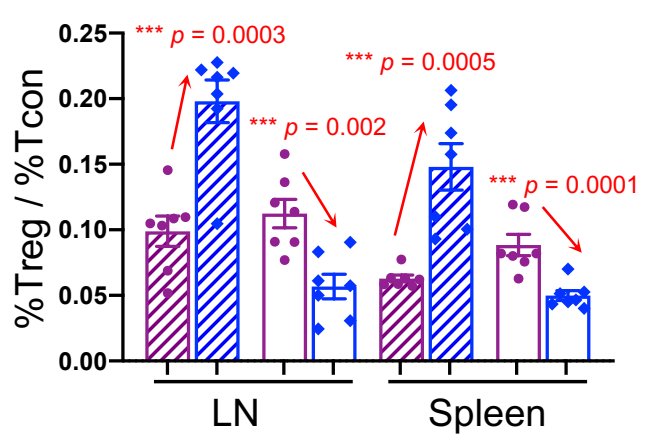

D.

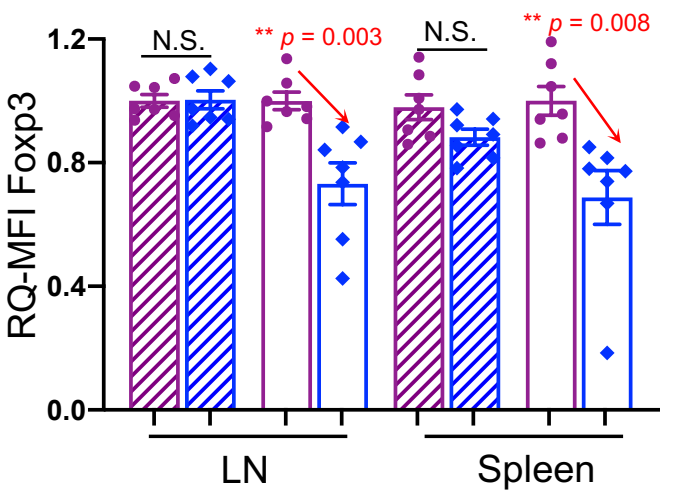

पाma Young Pan

पाm Aged Pan

$\square$ Young MOG-specific

$\square$ Aged MOG-specific

Figure 2. Imbalanced Pan- and MOG-specific Treg distributions in the periphery of late-onset EAE disease of aged mice 
A. in CD11b- in pan-CD4 pan-CD4 in MOG-specific

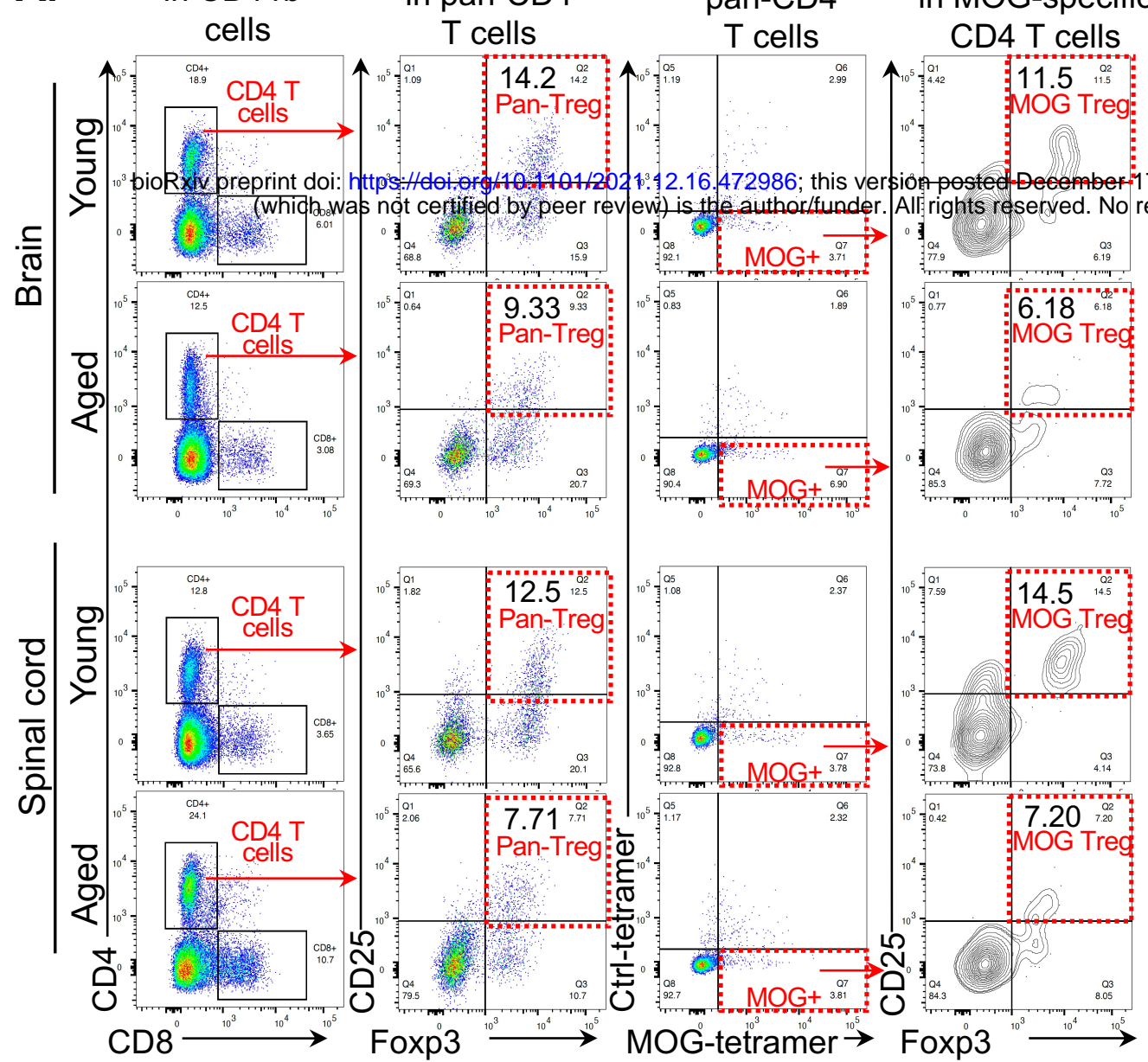

C.
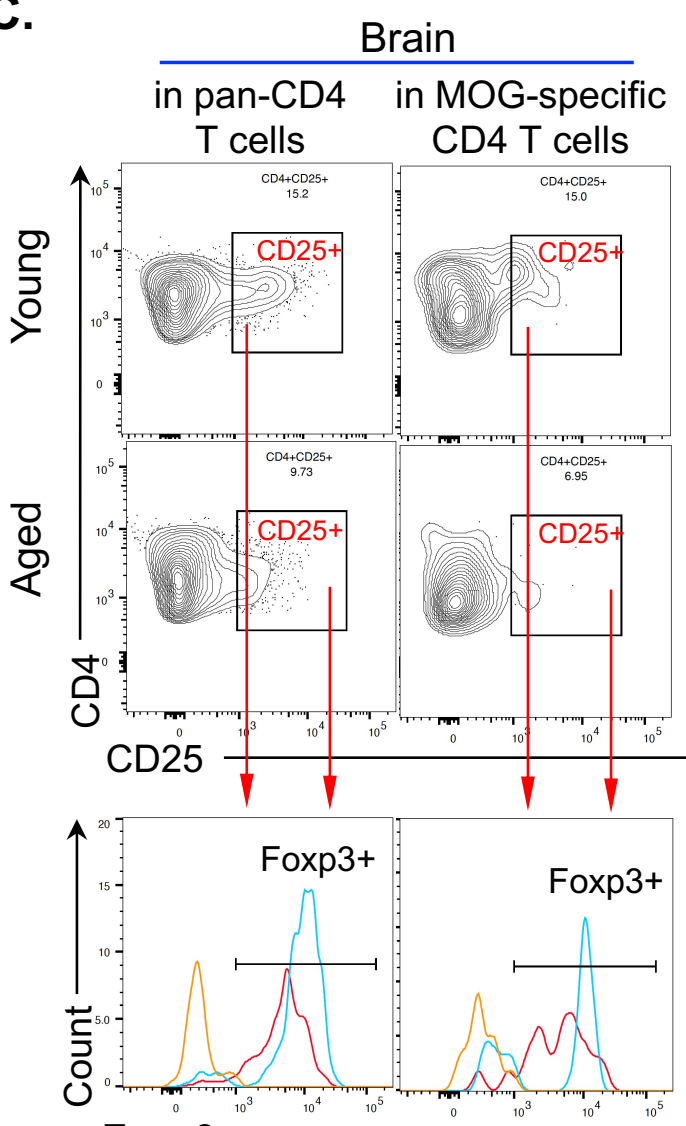

Foxp3

Spinal cord
B. Toung Pan

IIITA Aged Pan

Young MOG-specific Aged MOG-specific

20 ****

$p=0.0002 \quad p<0.0001^{* * *}{ }^{* * * *}$ 2021. The copyright holder:for this preprint $\leq 0.0001$
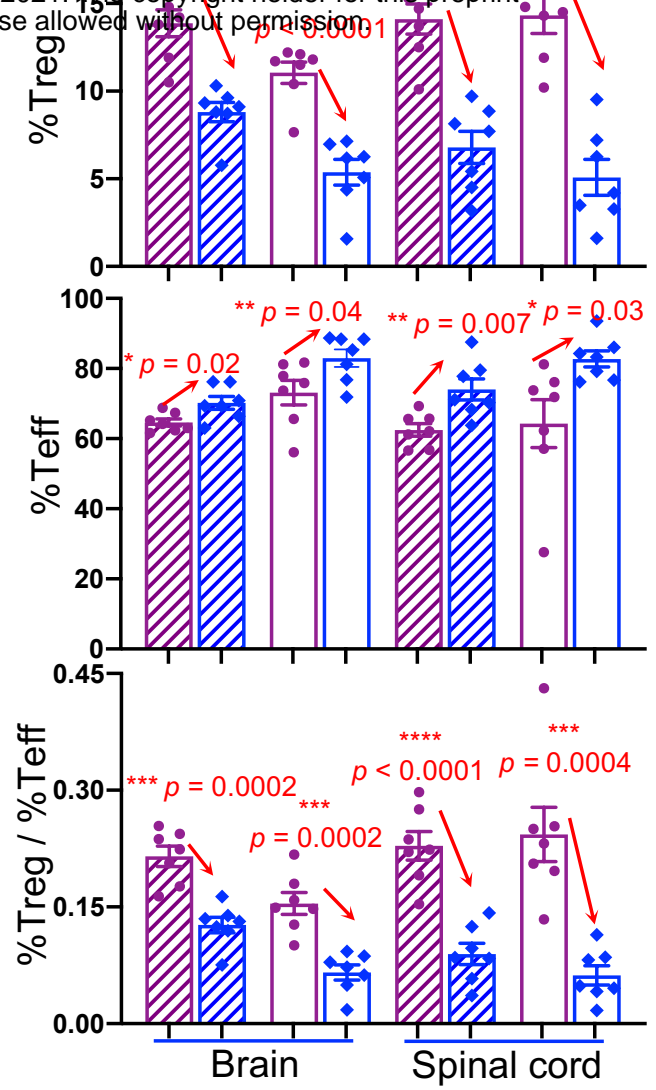

D.

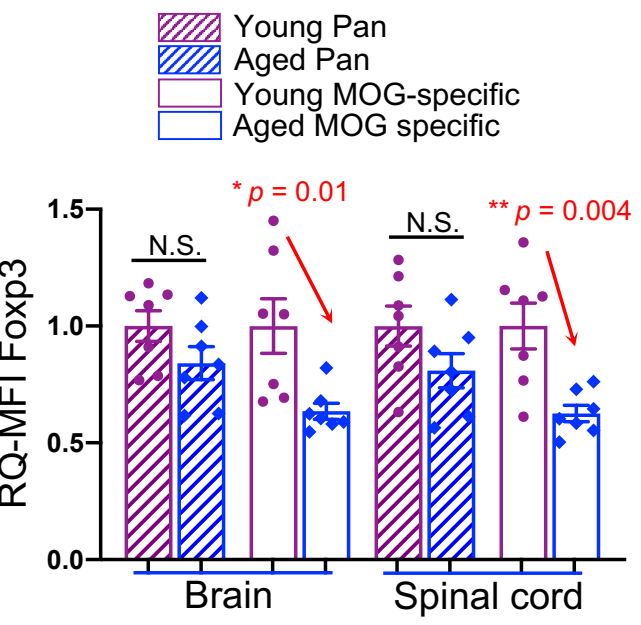

Young

- Aged

- Iso-ctr|

Figure 3. Imbalanced Pan- and MOG-specific Treg distributions in the CNS of late-onset EAE disease (30 - 35 days after immunization with MOG) of aged mice 
A. Transcardial PBS perfusion and CNS dissection (at 30dpi)

B.

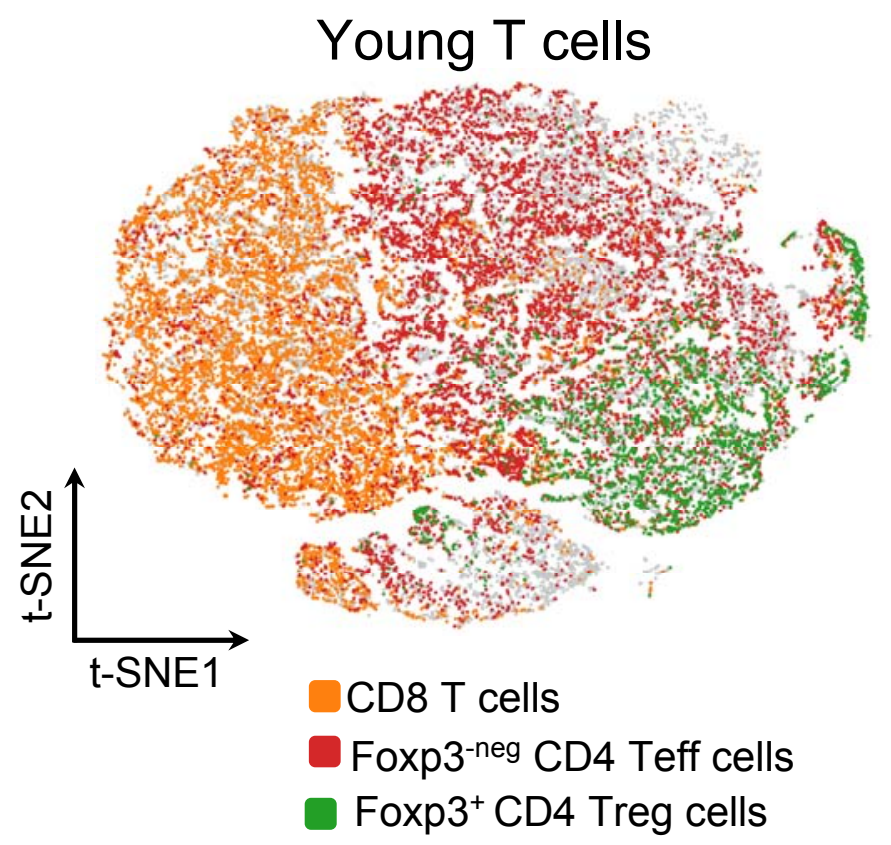

C.

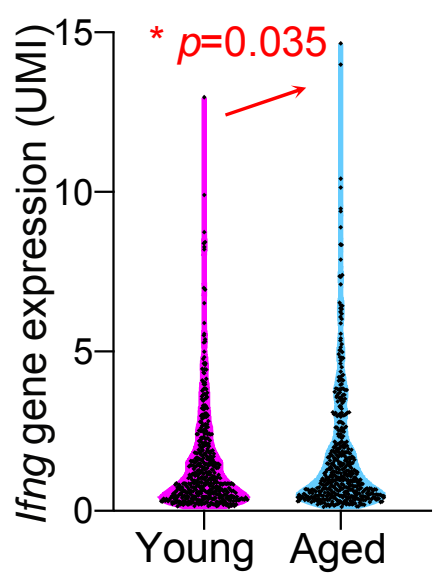

Isolate Mononuclear cells
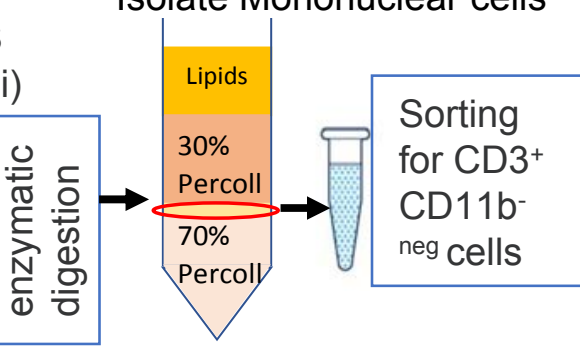

r.c.....

GEMs

(Gel Bead-In-Emulsions)

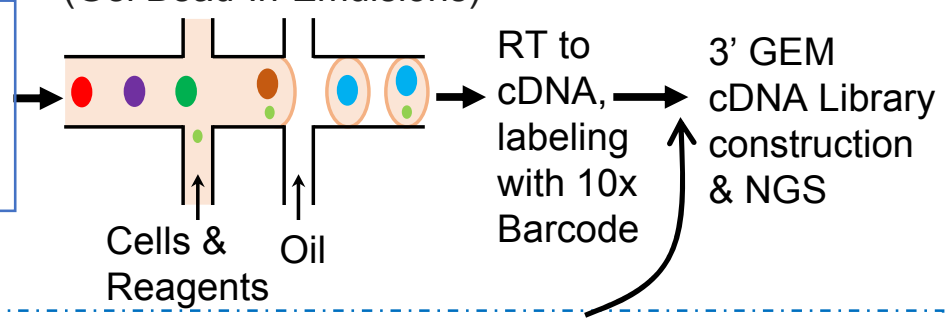

Cells \& Oi

TCR- primers for $\mathrm{V} \alpha \beta$ chains \& Oligo(dT) primers for gene expression profile

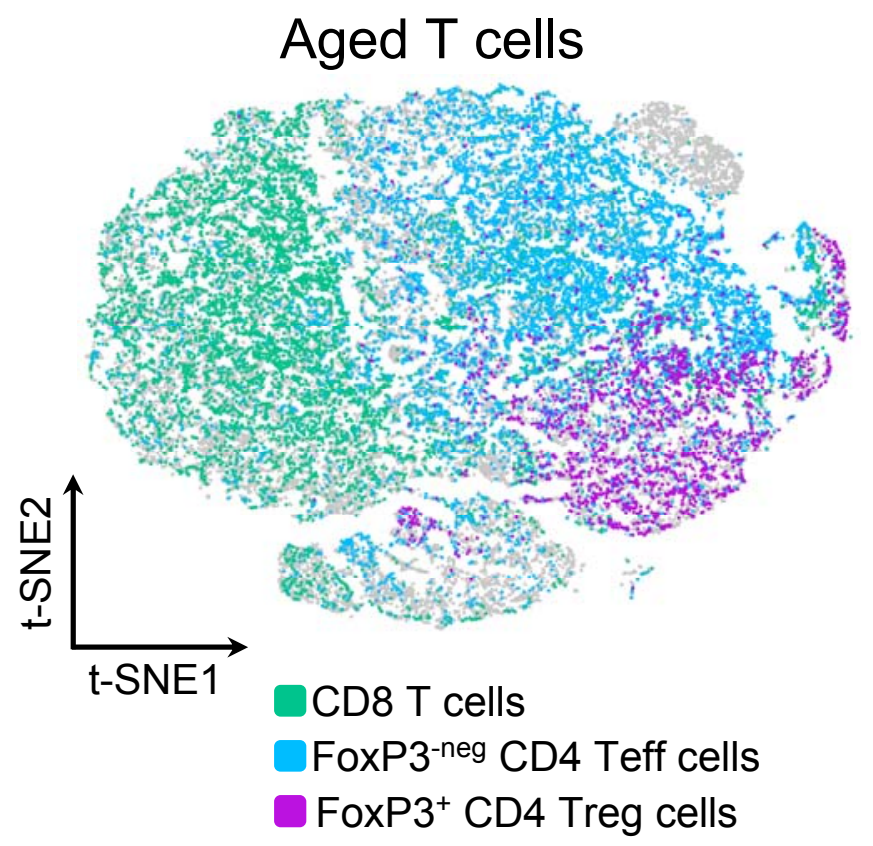

D.

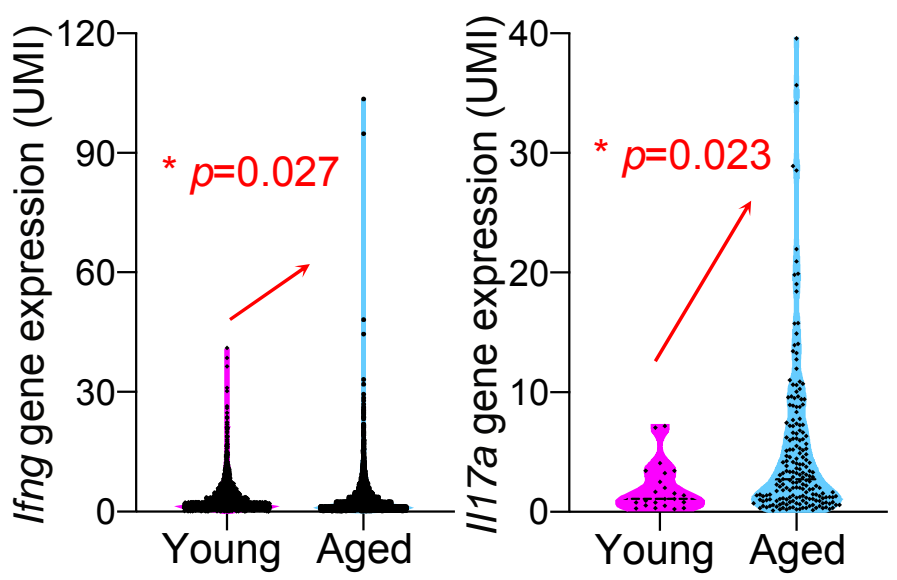

Fig. 4. Treg function-associated profile analysis of Treg plasticity and pro-inflammatory CD8 T cells in the aged CNS during EAE onset 
A.
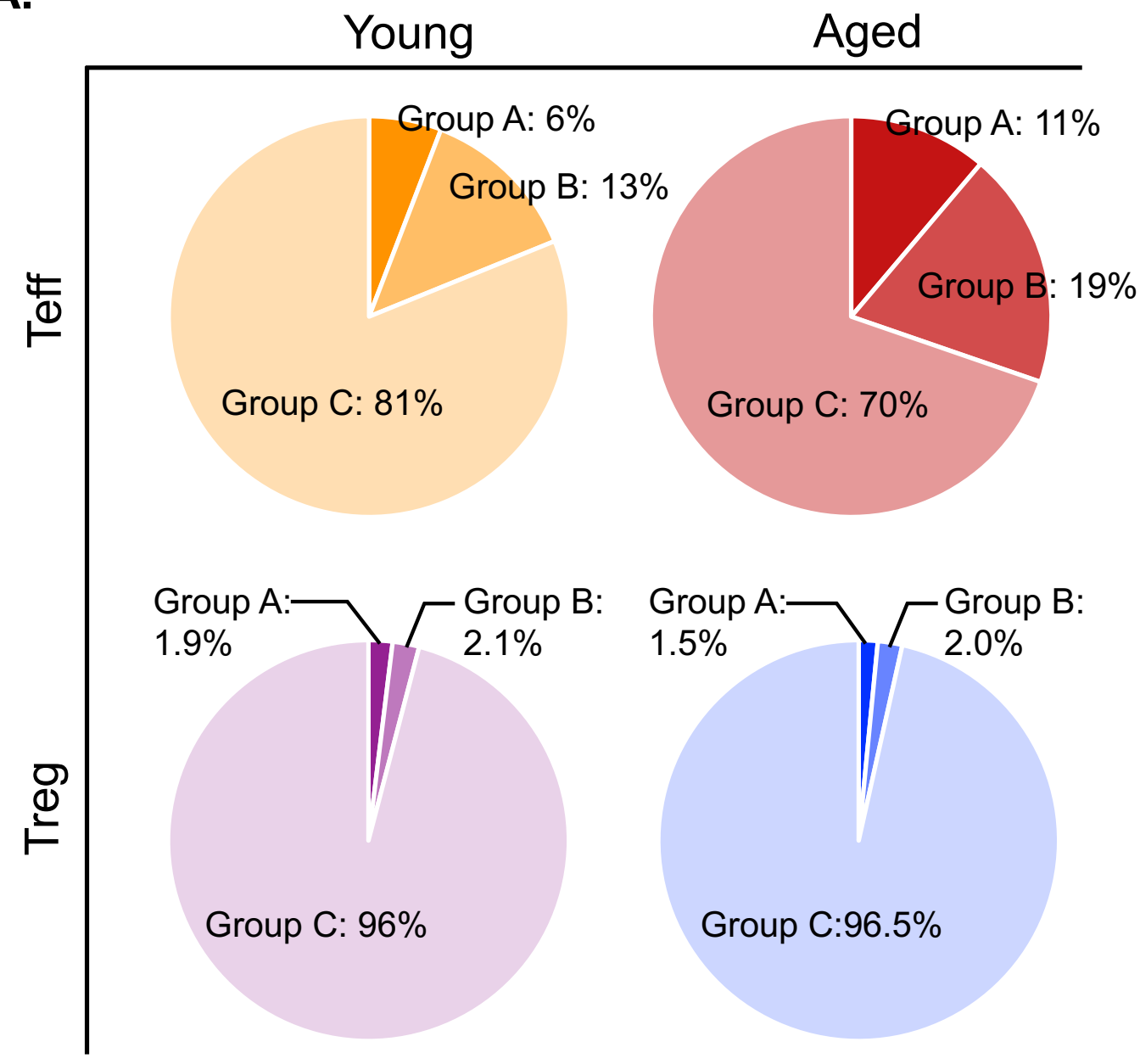

1. Expanded clones

Teff Treg

Group A:

Top10 expanded cones

Teff Treg

Group B:

Other expanded clones

\section{Unexpanded clones}

Teff Treg

Group C:

Single clones
B.

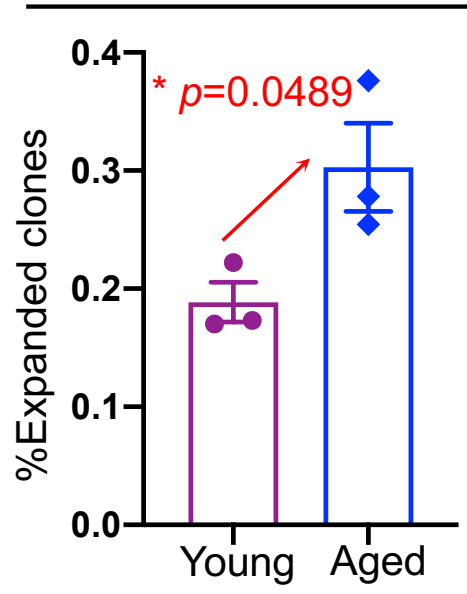

Teff

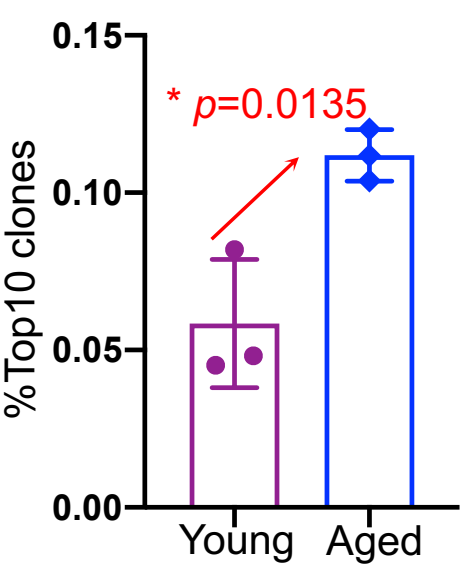

Treg

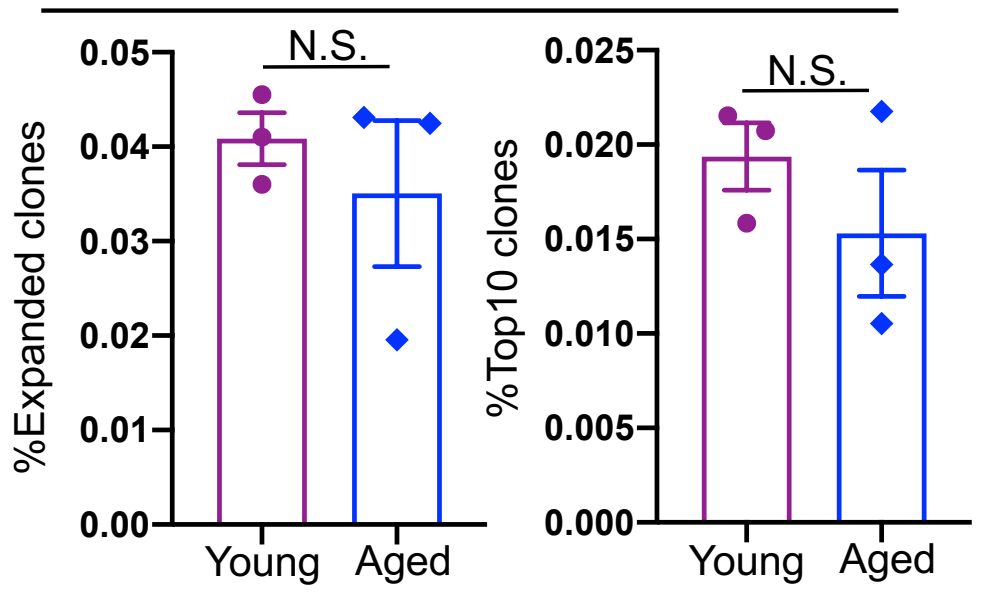

Fig. 5 Clonal expansion in CNS-infiltrated $\mathrm{CD} 4^{+} \mathrm{T}$ populations of young and aged mice during $\mathrm{EAE}$ 
A.

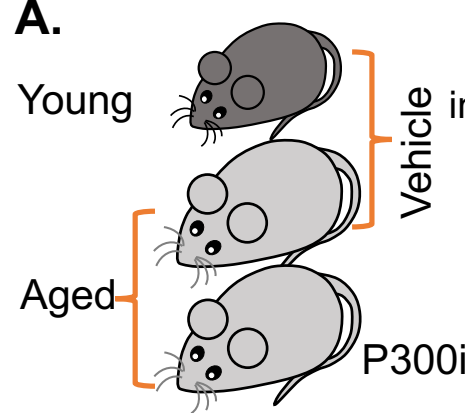

EAE

induction

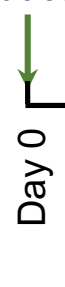

B.
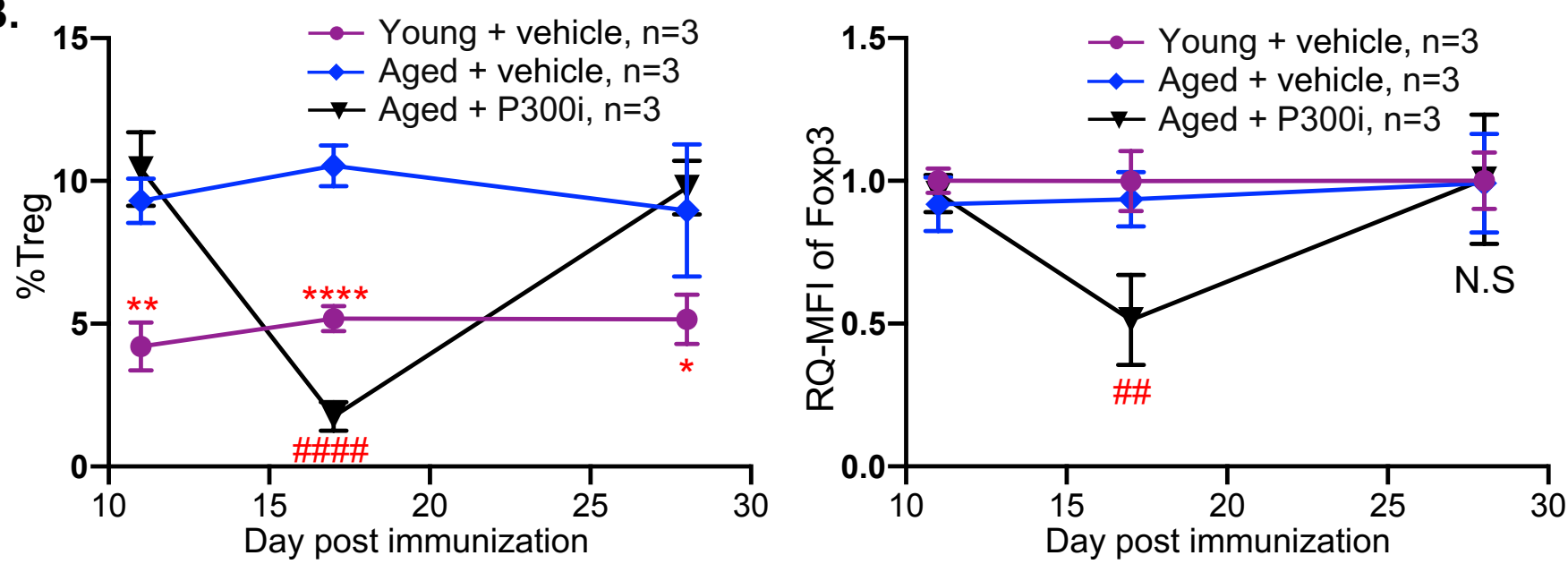

C.

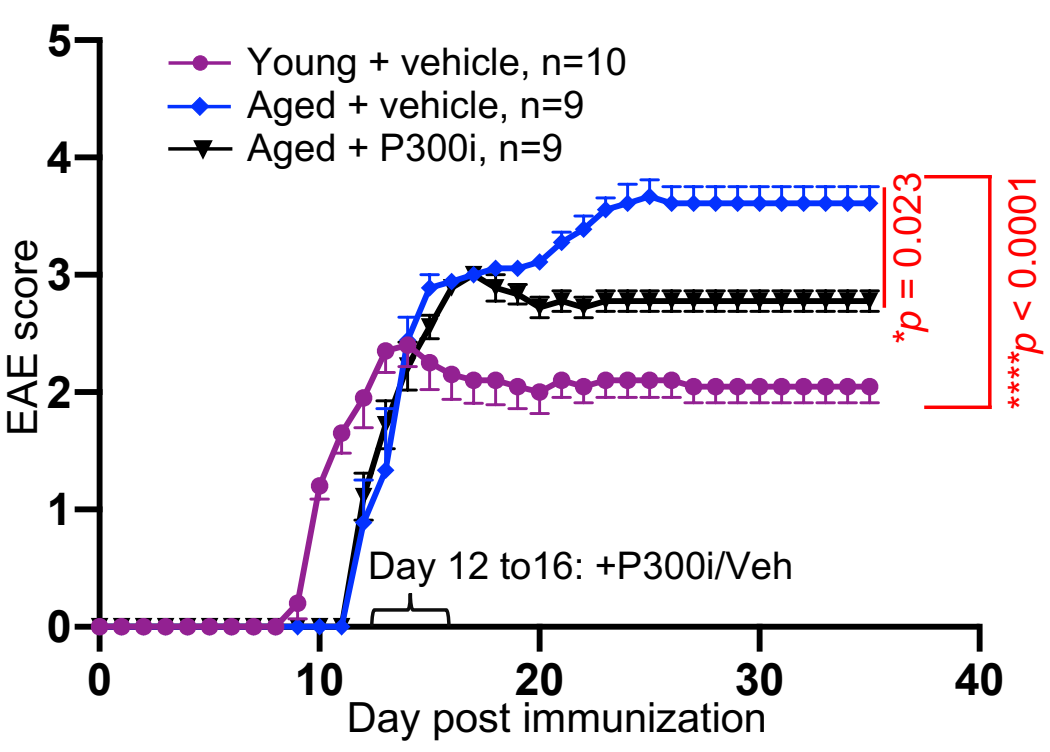

D.

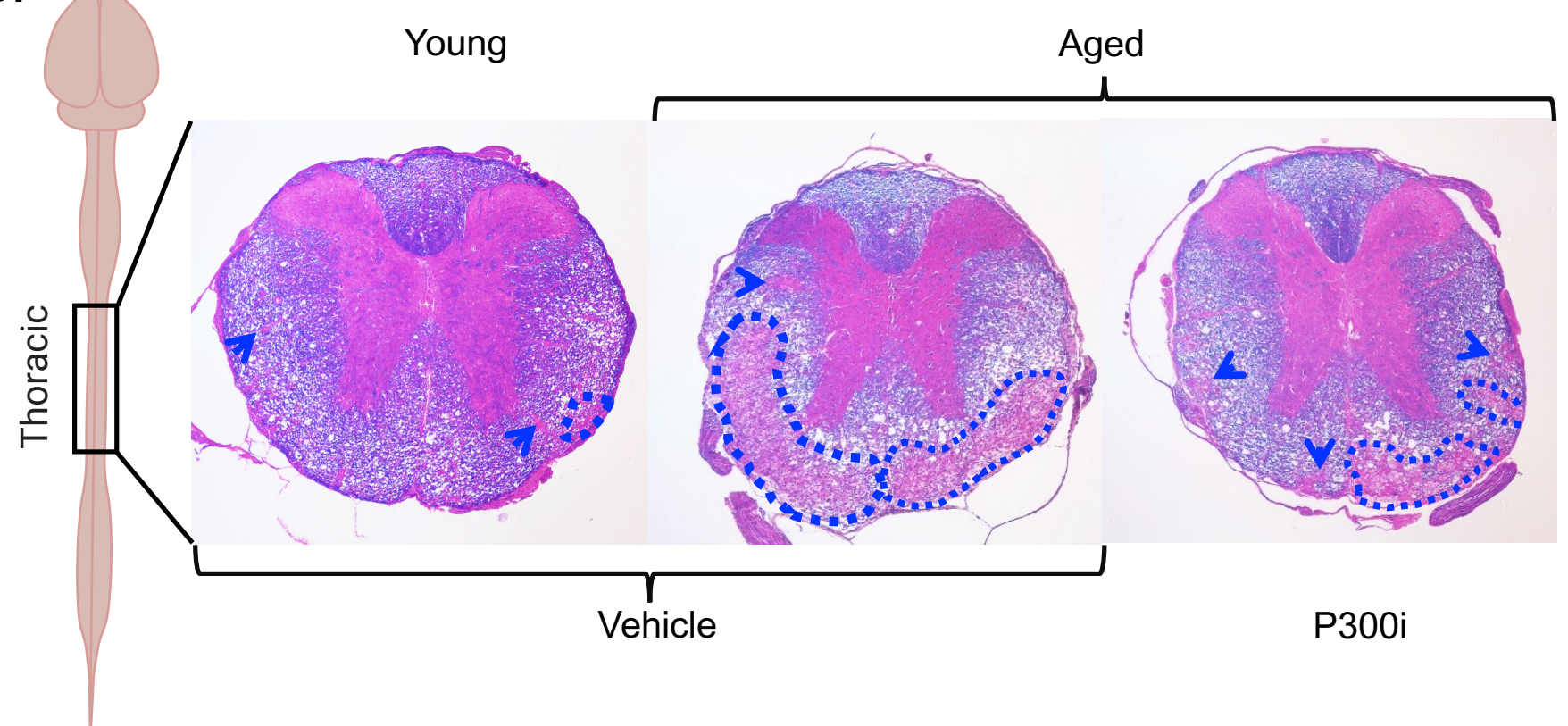

Fig. 6. Improvement of EAE severity after transient inhibition of pTreg cells in late-onset EAE in aged mice 
A.

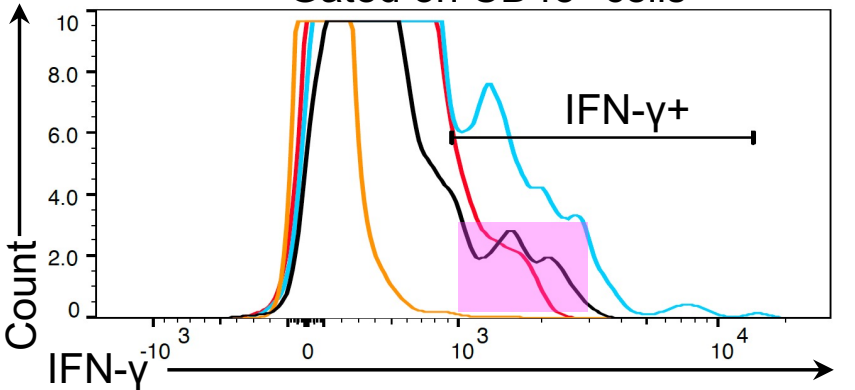

$\% \mathrm{IFN}-\gamma+$ cells IFN- $\mathrm{M} \mathrm{MFI}$

- Young + Veh: $19.3 \%, \quad 1503$

- Aged + Veh: $\quad 6.6 \%, \quad 1197$

- Aged + P300i: $\quad 16.5 \%, \quad 1500$

- Iso-ctr|

B. Gated on CD11b-neg In pan-CD4+ T cells

In pan-CD4 T cells in MOG-specific T cells
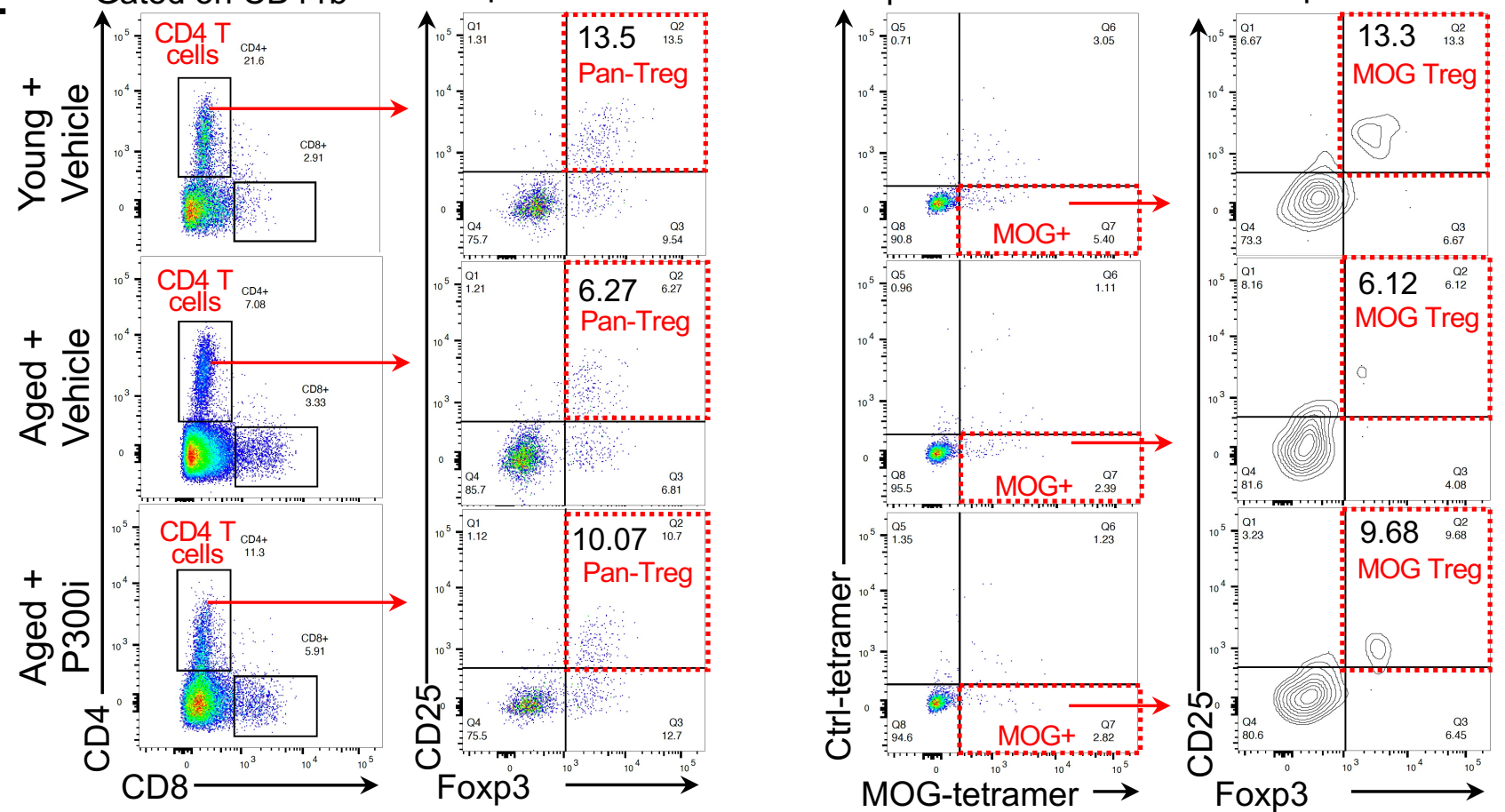

C. Vurts Young+Veh

$\square$ Young+Veh $\square$ Aged+Veh $\square$ Aged+P300i -specific -specific -specific
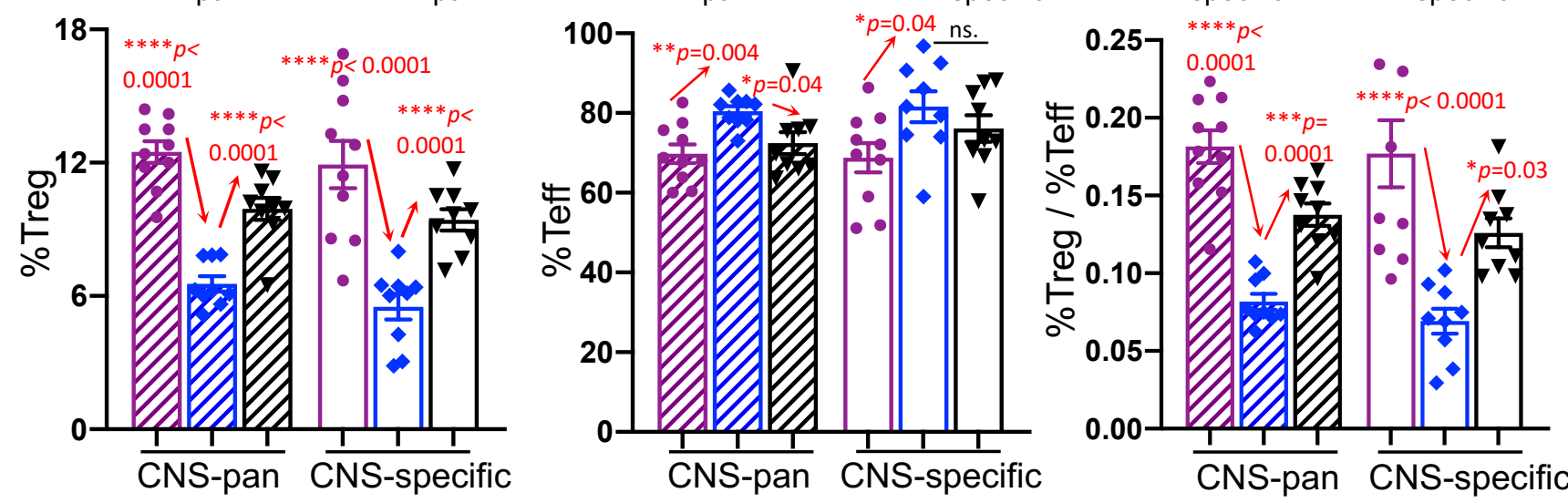

D.

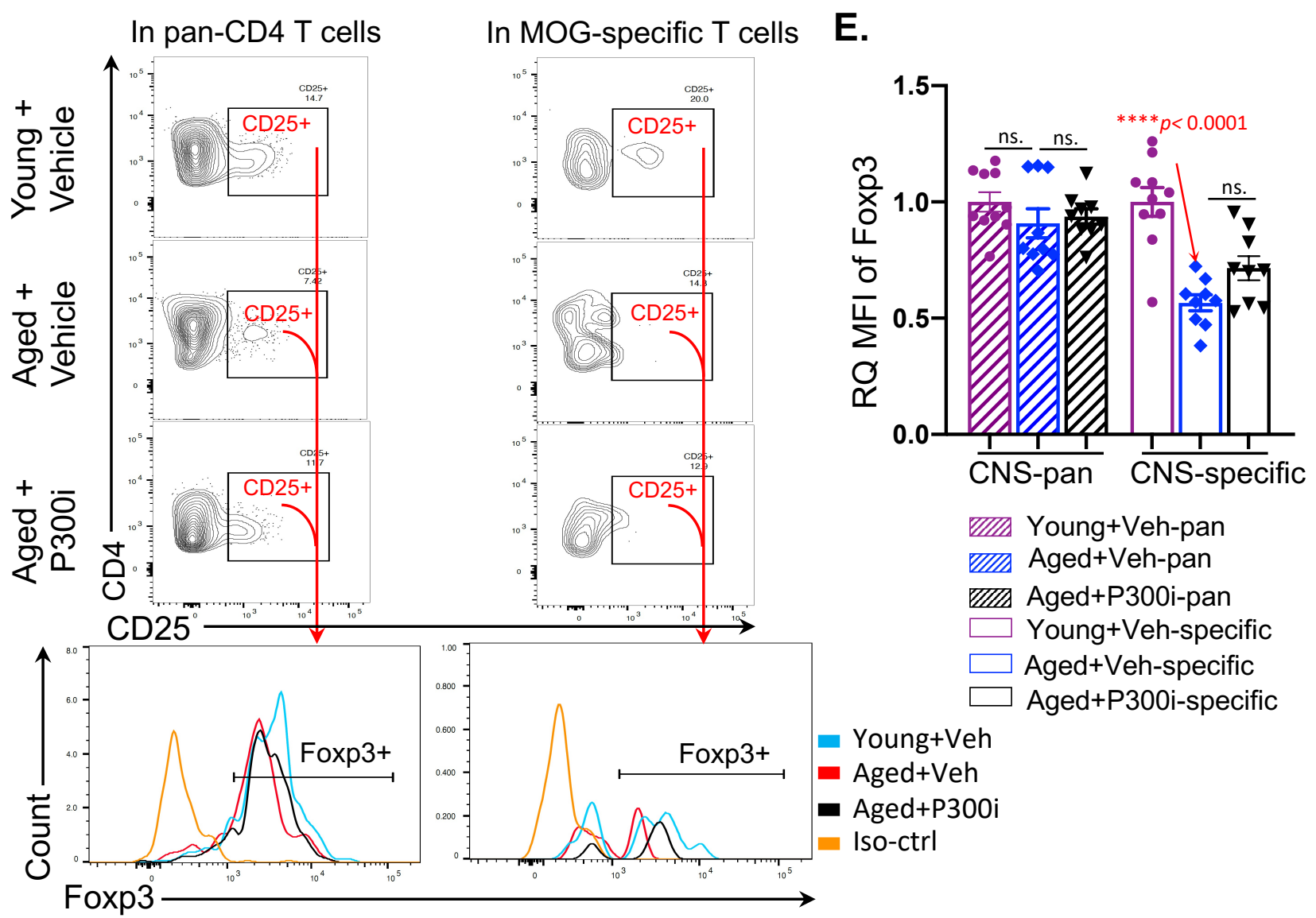

Fig. 7. Potential Mechanism of alleviation of late-onset EAE of aged mice after a transient and partial pTreg depletion 
A.

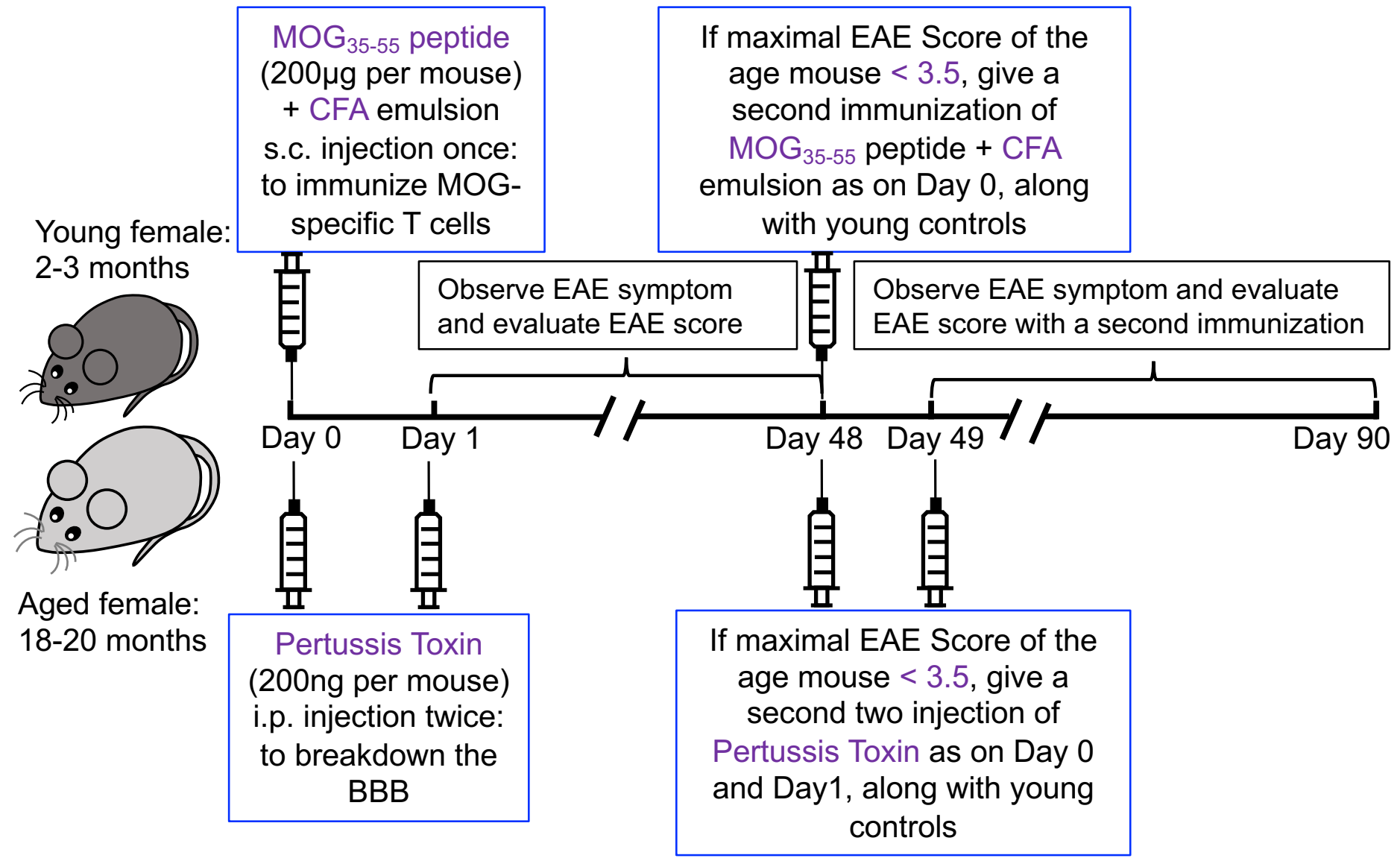

B.

C.
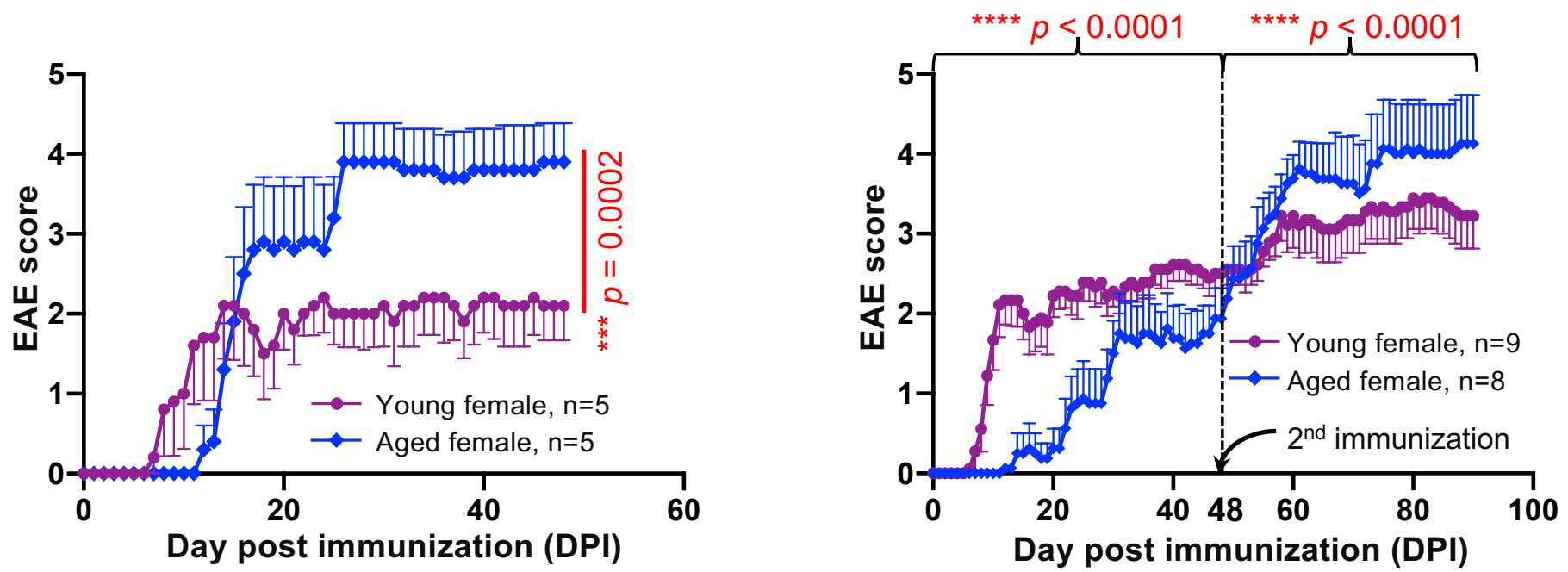

Supplemental Figure S1. Two types of EAE scores of aged female mice with equal dosage of MOG35-55 peptide as young mice. (A) Workflow for immunization and

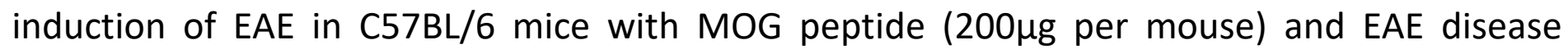
course observation. (B) Type-I EAE disease course in aged female mice with young female mice as control. (C) Type-II EAE disease course in aged female mice with young female mice as control. The $p$-values of EAE scores were calculated by MannWhitney $U$ test and a statistically significant difference was considered to be $p<0.05$. 
A
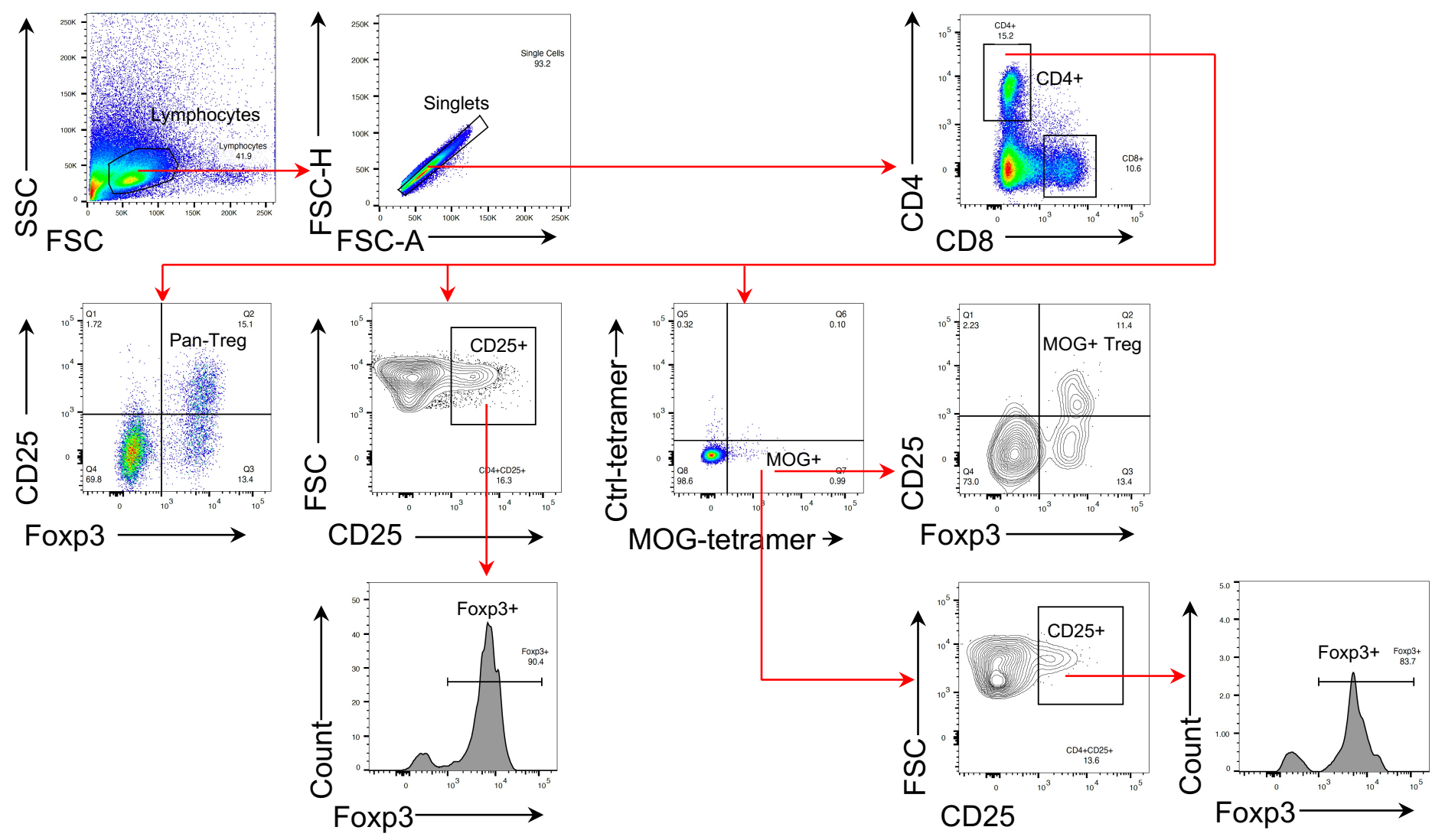

B
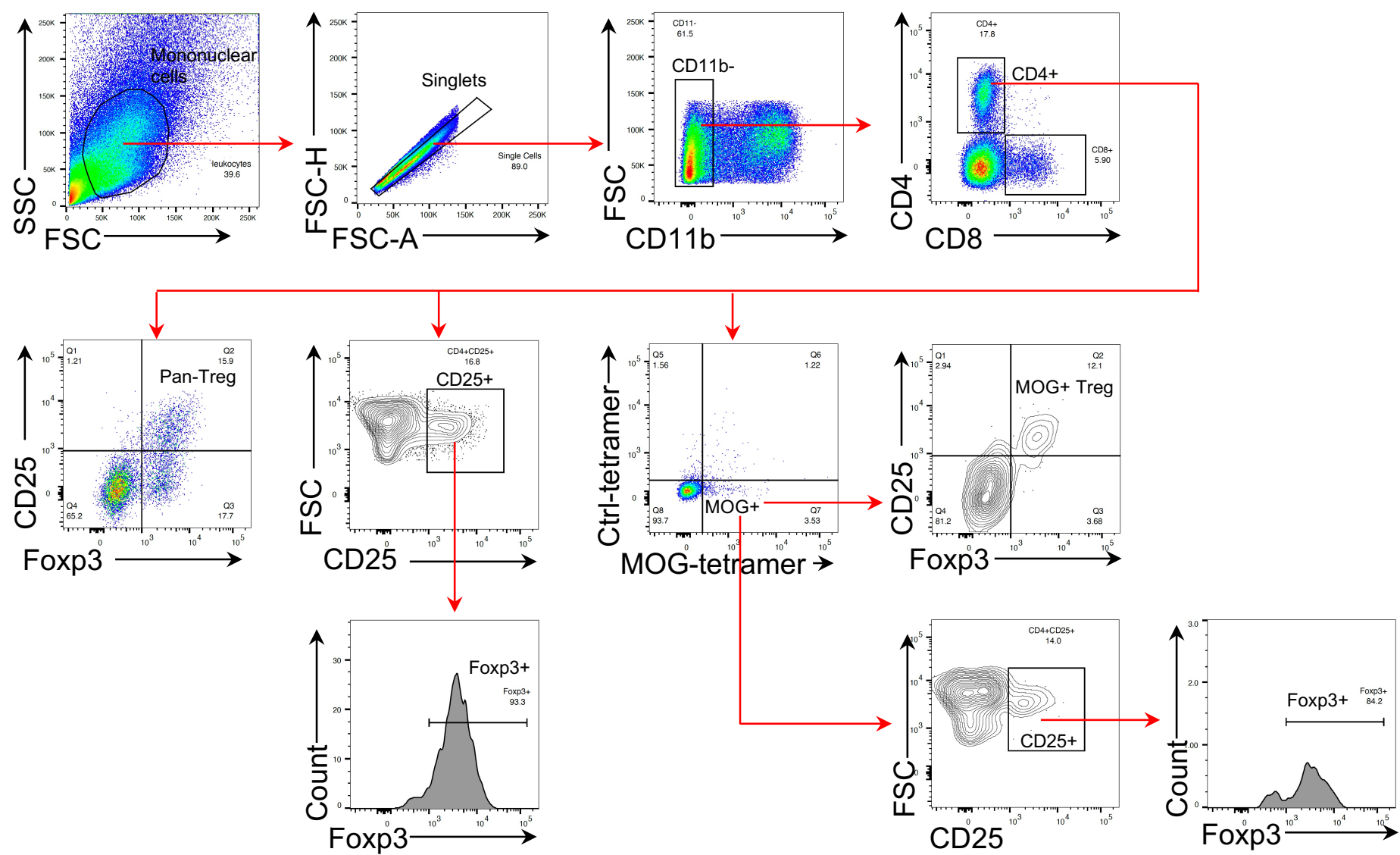

Supplemental Figure S2. Flow cytometric gating strategies of $T$ cell populations in the periphery and the CNS. (A) representative gating strategy for the T cell populations in the periphery (spleen/lymph node). (B) representative gating strategy for the $\mathrm{T}$ cell populations in the CNS (brain/spinal cord). 
A.

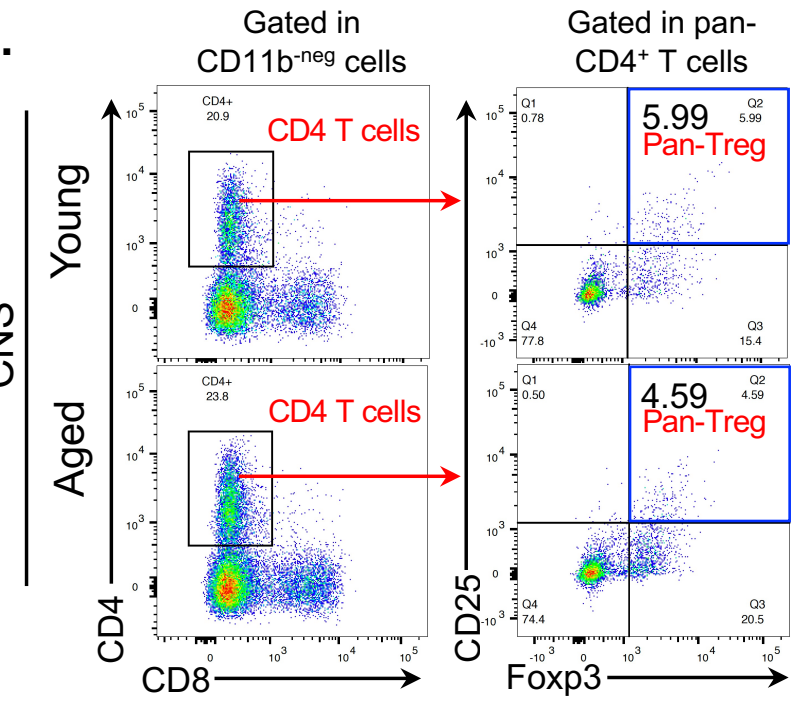

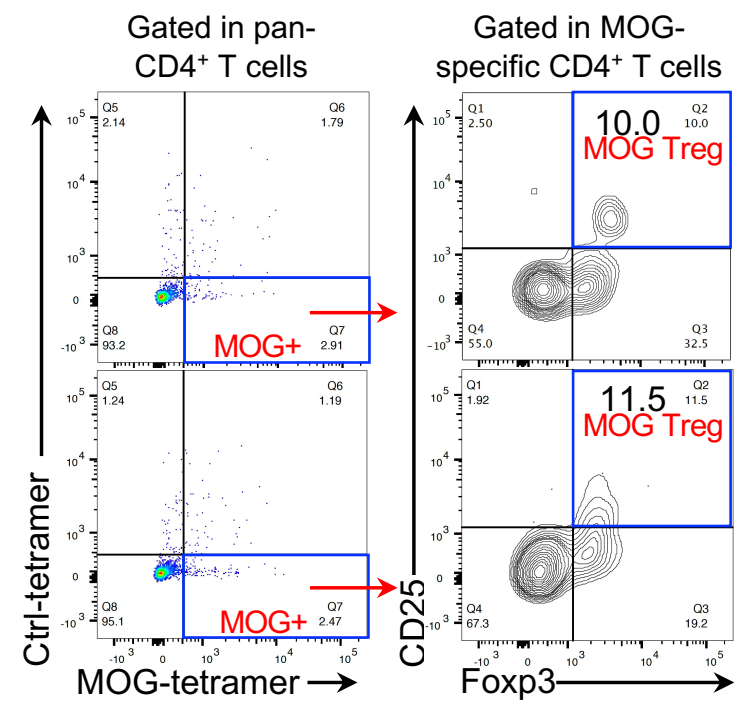

B.

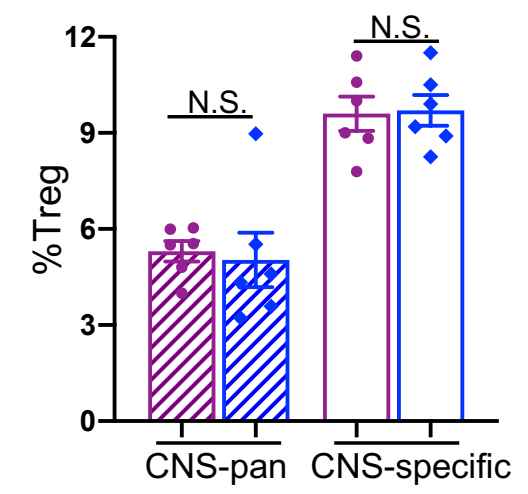

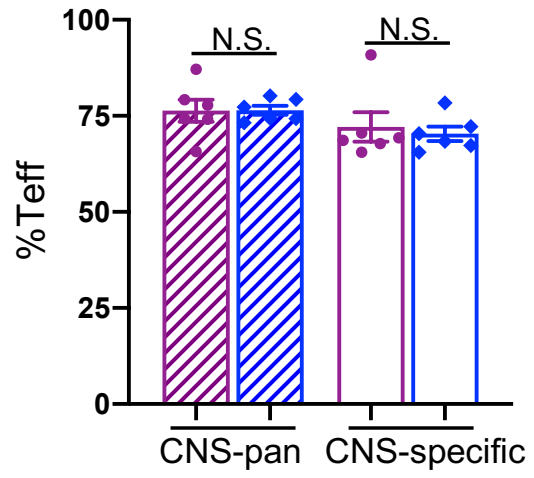

Gated in MOG specific$\mathrm{CD}^{+}{ }^{+} \mathrm{T}$ cells

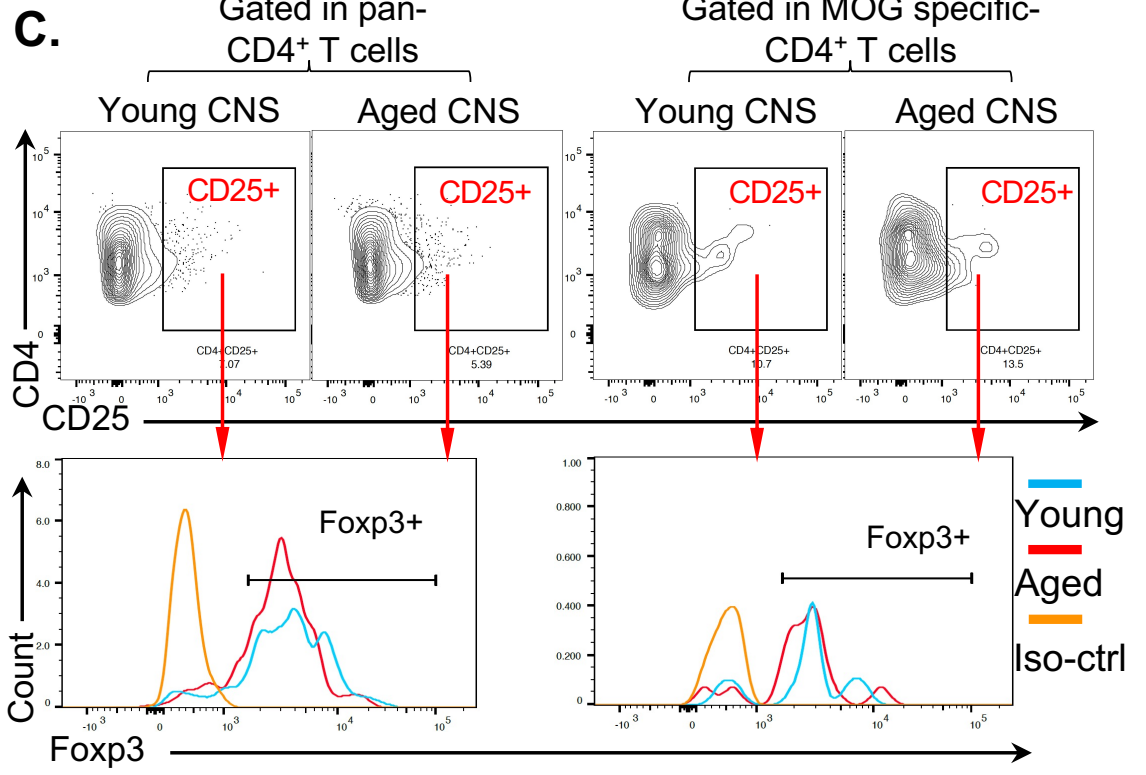

Aged MOG-specific

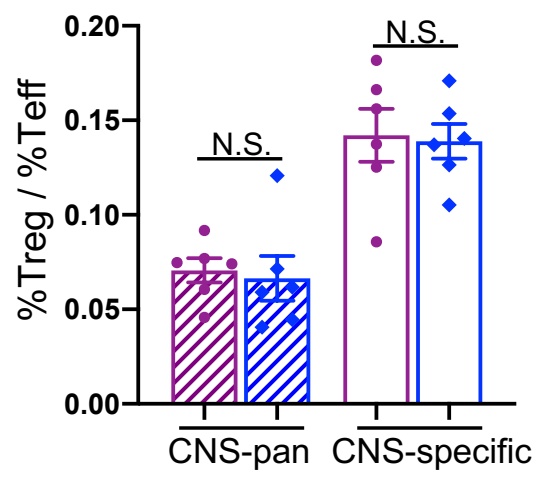

D. MIIA Young Pan WIIA Aged Pan $\square$ Young MOG-specific Aged MOG specific

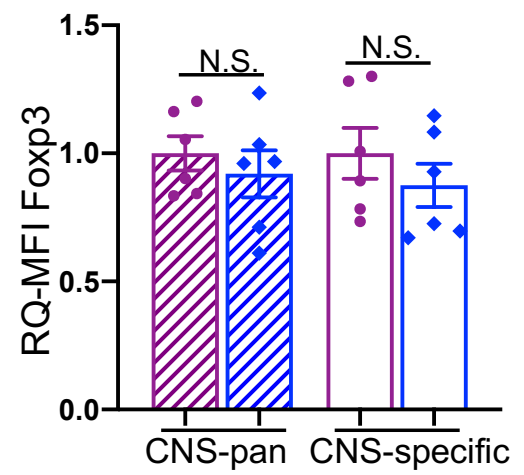

Supplemental Figure S3. Balanced pan- and MOG-specific Treg distributions in the CNS of lateonset EAE disease (8 days after immunization with MOG) in aged mice. (A) Flow cytometry gating strategies show pan-Treg population (left two columns) and MOG-specific Treg population (right two columns) in the CNS. (B) Summarized results of the percentages of pan- (striped bars) and MOG-specific (open bars) Treg cells (top panel) and Teff cells (middle panel), and ratios of Treg/Teff cells (bottom panel) in the CNS (brain and spinal cord) between young (cherry) and aged (blue) mice. (C) Flow cytometry gating strategies show representative FoxP3+ gates (bottom panels) from $\mathrm{CD} 4^{+} \mathrm{CD} 25^{+}$gates of the CNS (mix of brain and spinal cord) of young and aged mice. (D) Summarized results of the RQ-MFI of FoxP3 expression in pan- (striped bars) and MOG-specific (open bars) $\mathrm{CD} 4^{+} \mathrm{CD} 25^{+}$population in the CNS between young (cherry) and aged (blue) mice. In panels $B$ and $D$, each symbol represents an individual animal sample. The statistical significance between the two groups was analyzed by unpaired Student's $t$-test, "N.S." stands for "not significant", and error bars indicate mean \pm SEM. 
Young-1 Teff

A: $4.82 \%$

B: $12.21 \%$

$\mathrm{C}: 82.97 \%$

Young-2 Teff

A: $8.19 \%$

B: $14.03 \%$

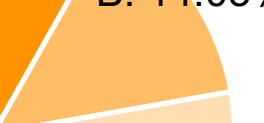

C: $77.78 \%$
Aged-1 Teff

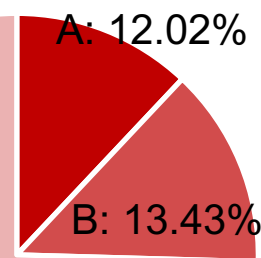

C: $82.97 \%$

Aged-2 Teff

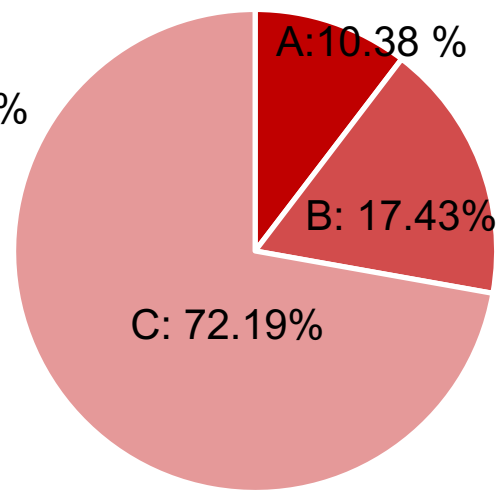

C: $72.19 \%$

Aged-3 Teff
A: $4.52 \%$

B: $12.79 \%$

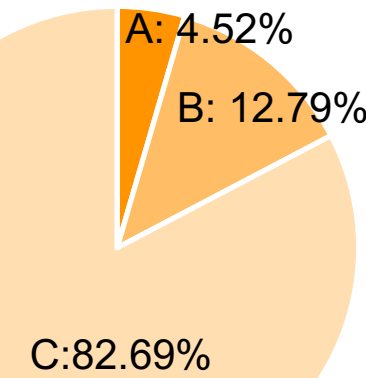

C:82.69\%

Young-3-Teff

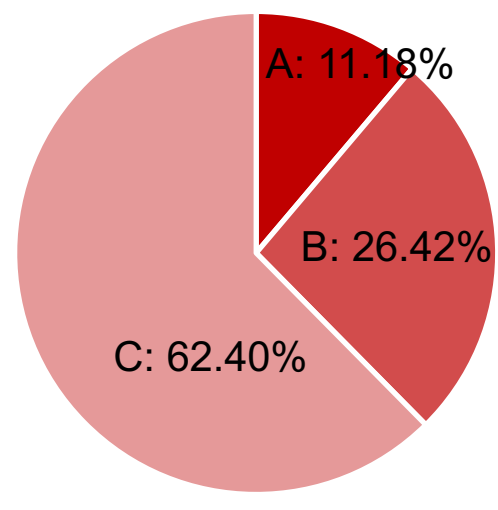

1. Expanded clones

Teff Treg

Group A: Top10 expanded cones

Teff Treg
Young-1 Treg
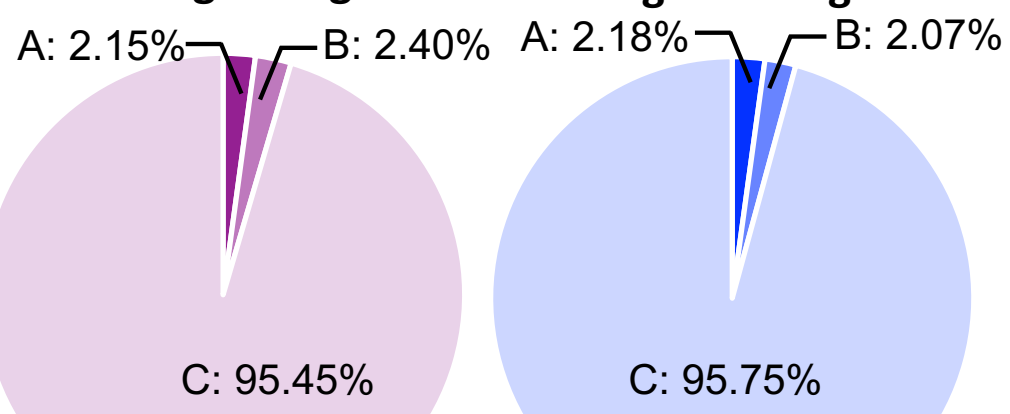

Young-2 Treg

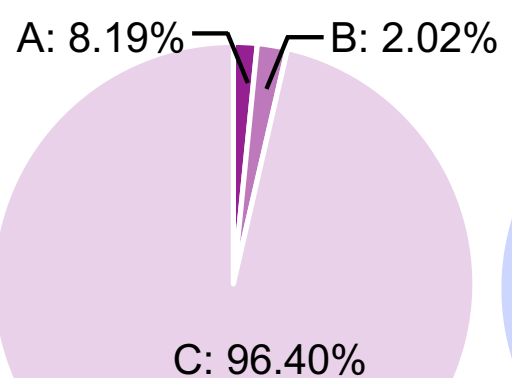

Aged-2 Treg

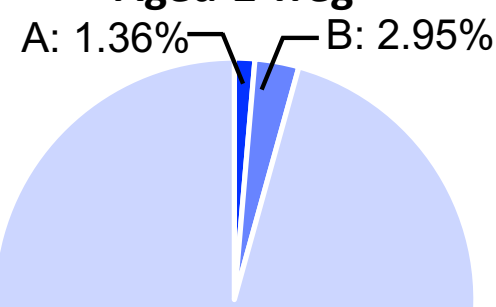

C: $95.69 \%$
Young-3 Treg

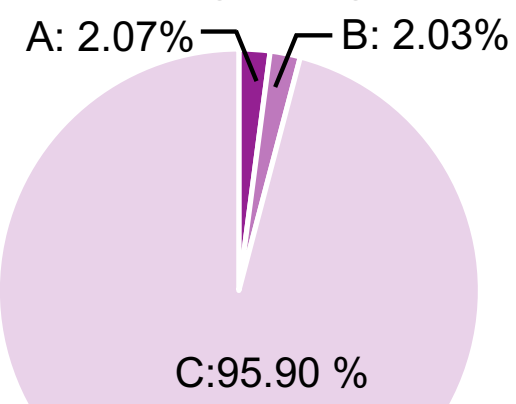

Aged-3 Treg

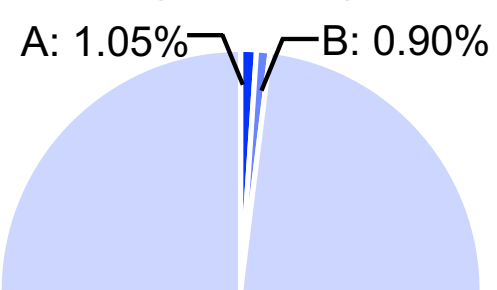

C: $98.04 \%$
2. Unexpanded clones

Teff $\stackrel{\text { Treg }}{\square}$ Group C: Single clones

Group B: Other expanded clones

Supplemental Figure. S4. Clonal expansion in CNS-infiltrated CD4 ${ }^{+} \mathrm{T}$ populations of individual young and aged mice during EAE. Leftmost column: individual pie charts of young Teff cell clonal expansion; second left column: individual pie charts of aged Teff cell clonal expansion; second right column: individual pie charts of young Treg cell clonal expansion; rightmost column: individual pie charts of aged Treg cell clonal expansion. 
A

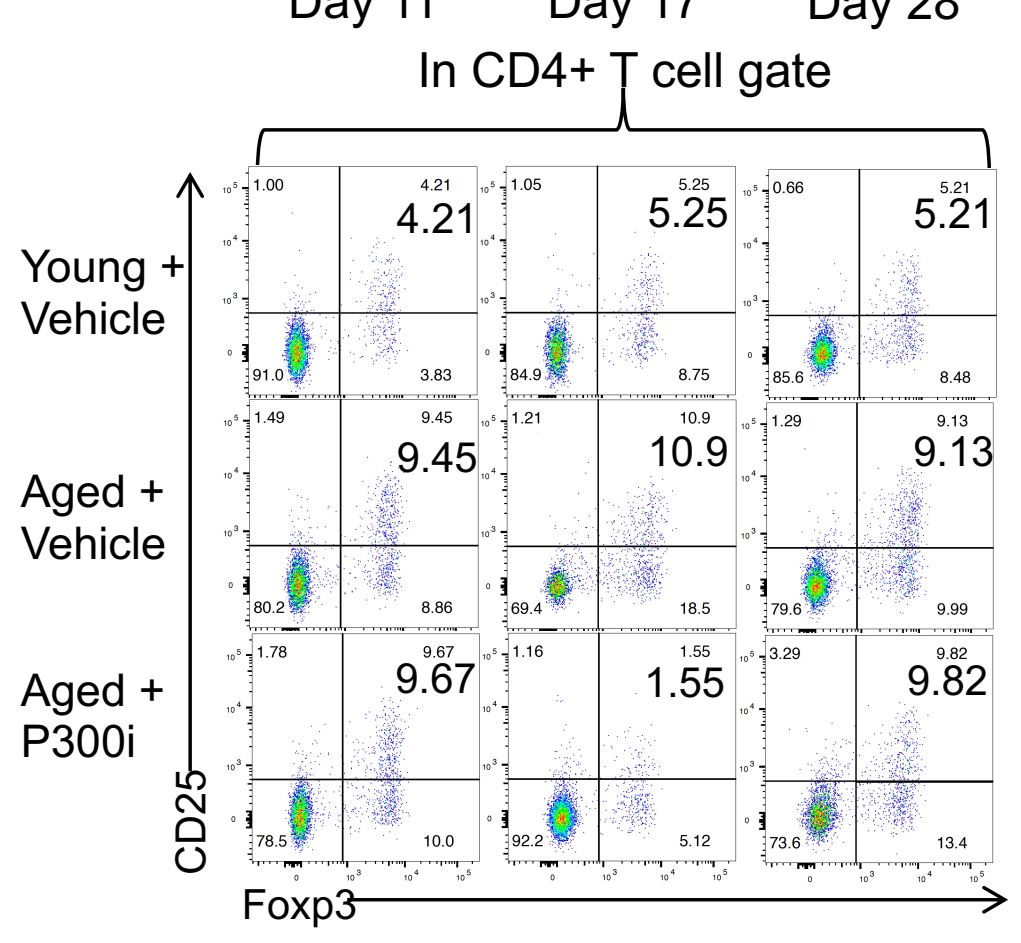

B

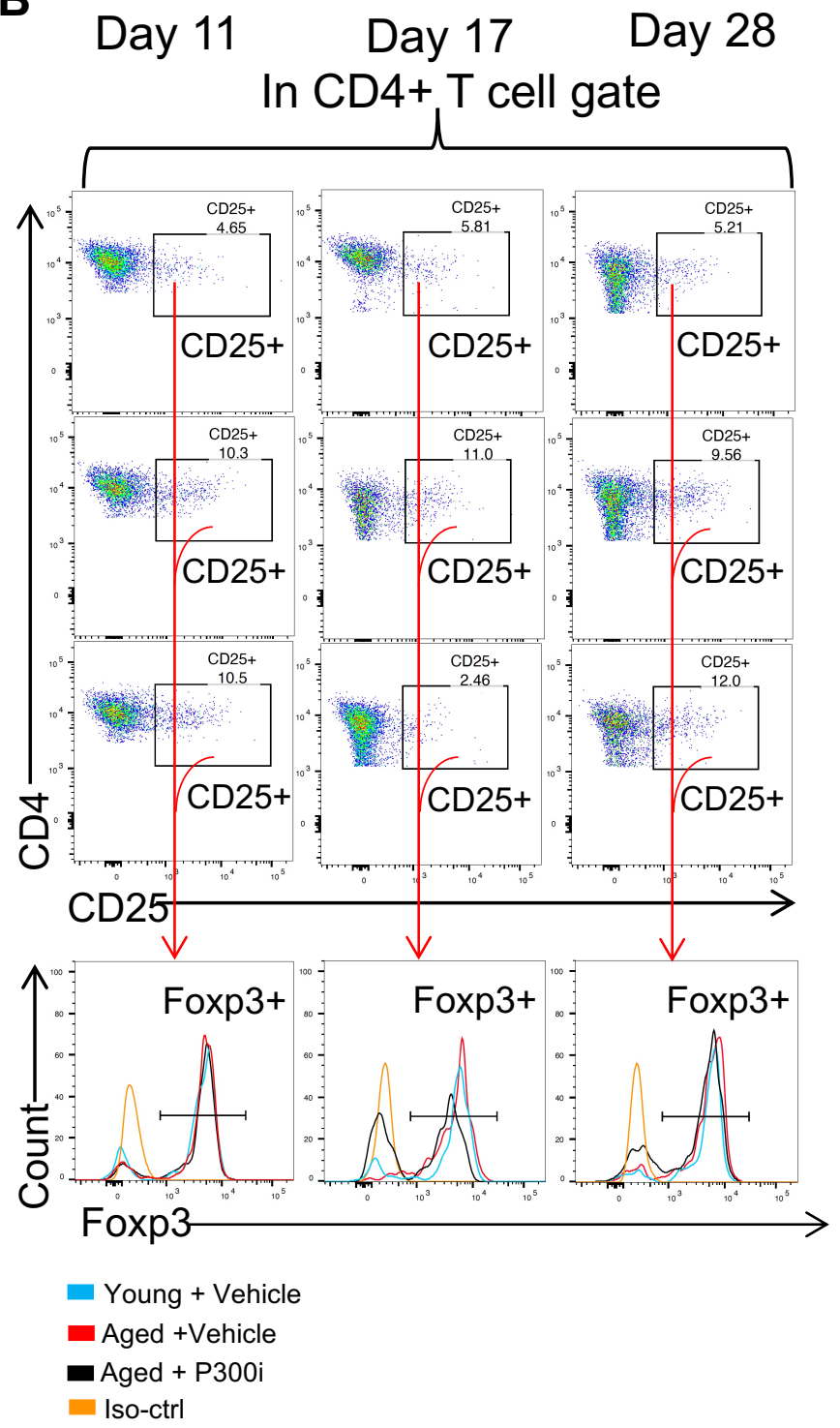

Supplemental Figure S5. Gating strategies of peripheral blood Treg cell dynamics during partial and transient depletion of pTreg cells. (A) Flow cytometry gating strategies show the frequencies of peripheral blood Treg cells in the three groups of mice 11-DPI (one day before p300i or vehicle treatment), 17-DPI (one day after the last p300i or vehicle treatment) and 28-DPI (12 days

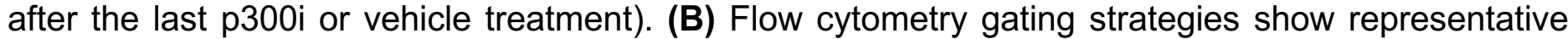
FoxP3+ gates (bottom panels) from CD4+CD25+ gates of the peripheral blood Treg cells in the three groups of mice 11-DPI, 17-DPI, and 28-DPI. 
A.

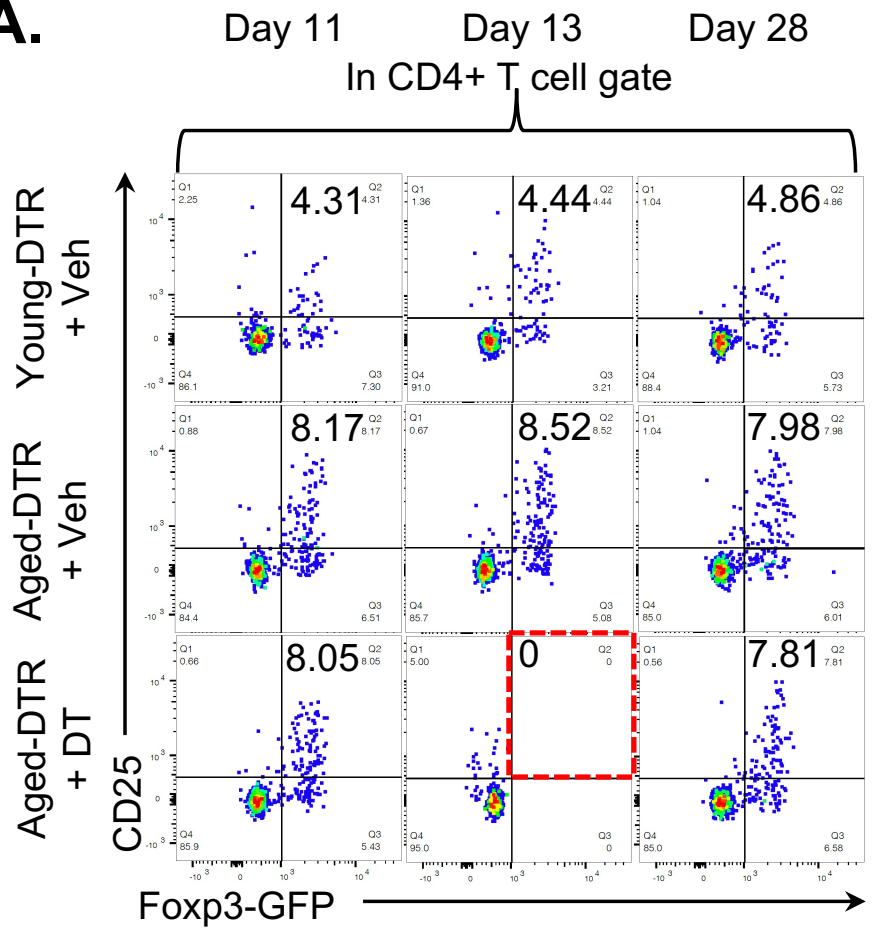

B.

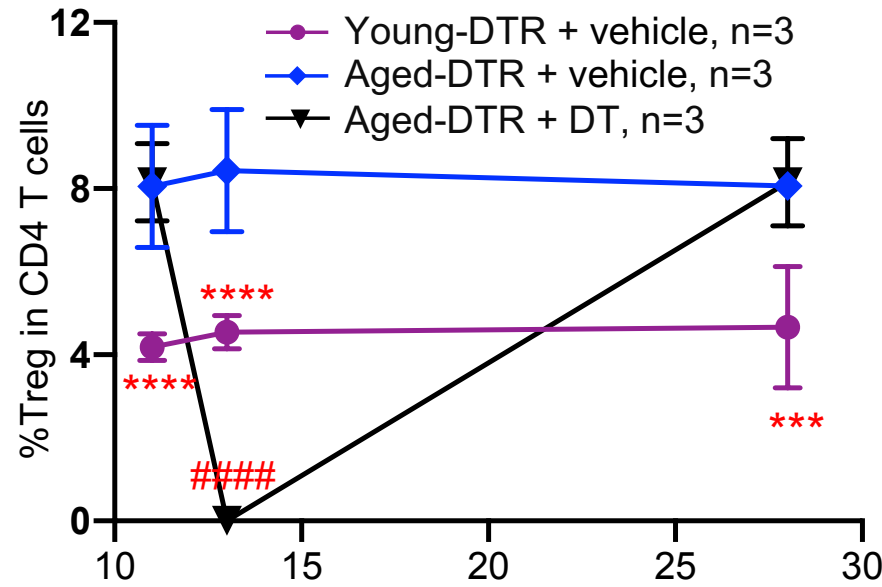

C.

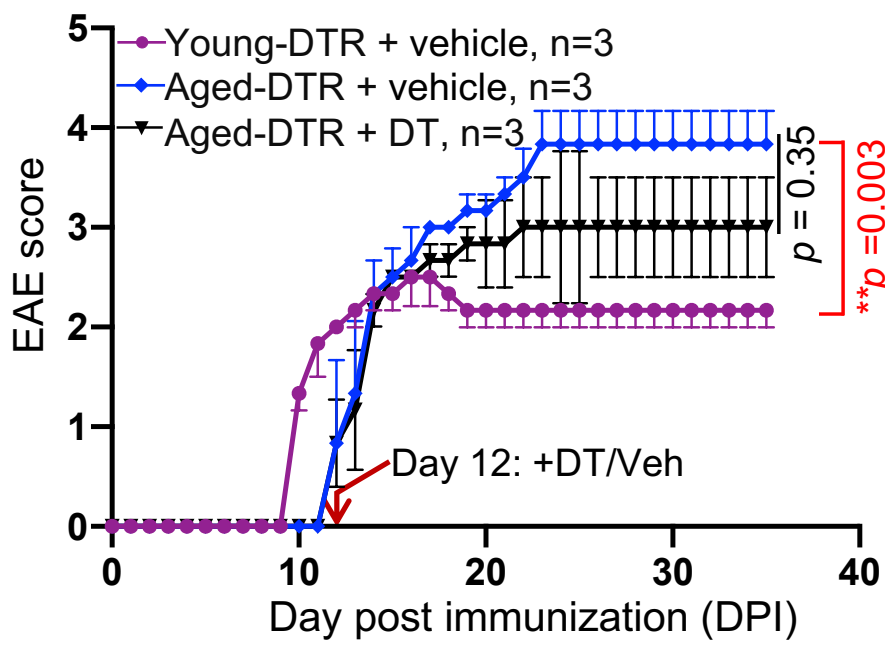

D.
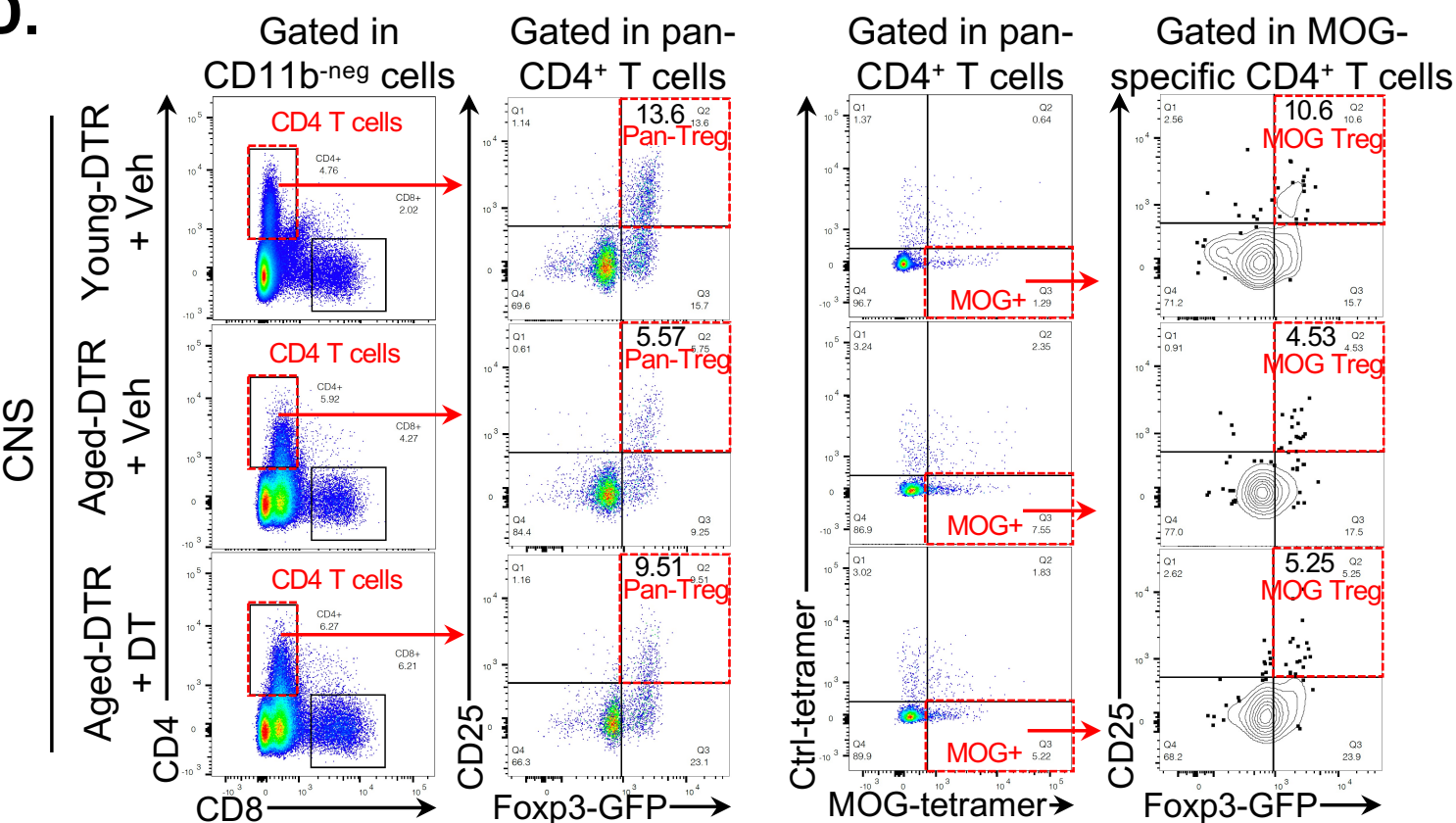

Supplemental Figure. S6. Alleviation of EAE severity after transient depletion of accumulated pTreg cells in late-onset EAE in aged Foxp3-DTR mice. (A) Flow cytometry gating strategies show the frequencies of peripheral blood Treg cells in the three groups of mice 11-DPI (one day before DT or vehicle treatment), 13-DPI (one day after DT or vehicle treatment) and 28-DPI (16 days after DT or vehicle treatment). (B) Summarized results of dynamic changes of Treg frequencies in the peripheral blood of three groups of mice. All data are expressed as mean \pm SEM and are analyzed by One-way ANOVA followed by Dunnett's multiple post-hoc test. ${ }^{* * * *} p<0.0001$, youngDTR mice +vehicle v.s. Aged-DTR mice +vehicle; ${ }^{* * *} p<0.001$, young-DTR mice + vehicle v.s. Aged-DTR mice + vehicle; \#\#\# $p<0.0001$, aged-DTR mice + vehicle v.s. aged-DTR mice + DT. Animal numbers in each group are listed in each panel. (C) Alleviation of the symptoms in late-onset EAE of aged-DTR mice. The $p$-values were calculated with Kruskal-Wallis test followed by Dunnett's multiple comparisons post hoc test for pairwise comparisons of groups, with $p<0.05$ as statistically significant. (D) Flow cytometry pan-Treg and MOG-specific Treg cells in the CNS of young-DTR and aged-DTR mice with DT or vehicle treatment. 


\section{Supplemental Methods:}

A. Table S1: Mouse EAE scoring

\begin{tabular}{|l|l|}
\hline Score & Clinic observations \\
\hline 0 & No obvious changes in motor function compared to non-immunized mice \\
\hline 0.5 & tail tip limpness \\
\hline 1.0 & tail limpness \\
\hline 1.5 & tail limpness and hind leg inhibition \\
\hline 2.0 & partial hind leg paralysis \\
\hline 2.5 & partial hind leg paralysis with dragging of at least one hind leg \\
\hline 3.0 & complete paralysis of hind legs \\
\hline 3.5 & complete hind leg paralysis and unable to right the body when placed on the side \\
\hline 4.0 & complete hind leg and partial front leg paralysis \\
\hline 4.5 & complete hind leg and partial front leg paralysis and mouse is not alert \\
\hline 5.0 & spontaneously rolling in the cage or death \\
\hline
\end{tabular}

https://hookelabs.com/protocols/eaeAI_C57BL6.html

\section{B. Luxol fast blue (LFB) staining * of demyelinated spinal cord with/without Eosin counterstaining}

Slides of spinal cord paraffin section ( $5 \mu \mathrm{m}$ thick)

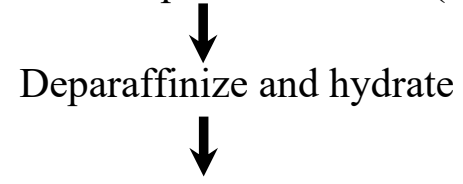

Incubate with $0.1 \%$ LFB solution, overnight at $60^{\circ} \mathrm{C}$

Differentiate with $0.5 \%$ lithium carbonate solution, $1 \mathrm{~min}$ at room temperature
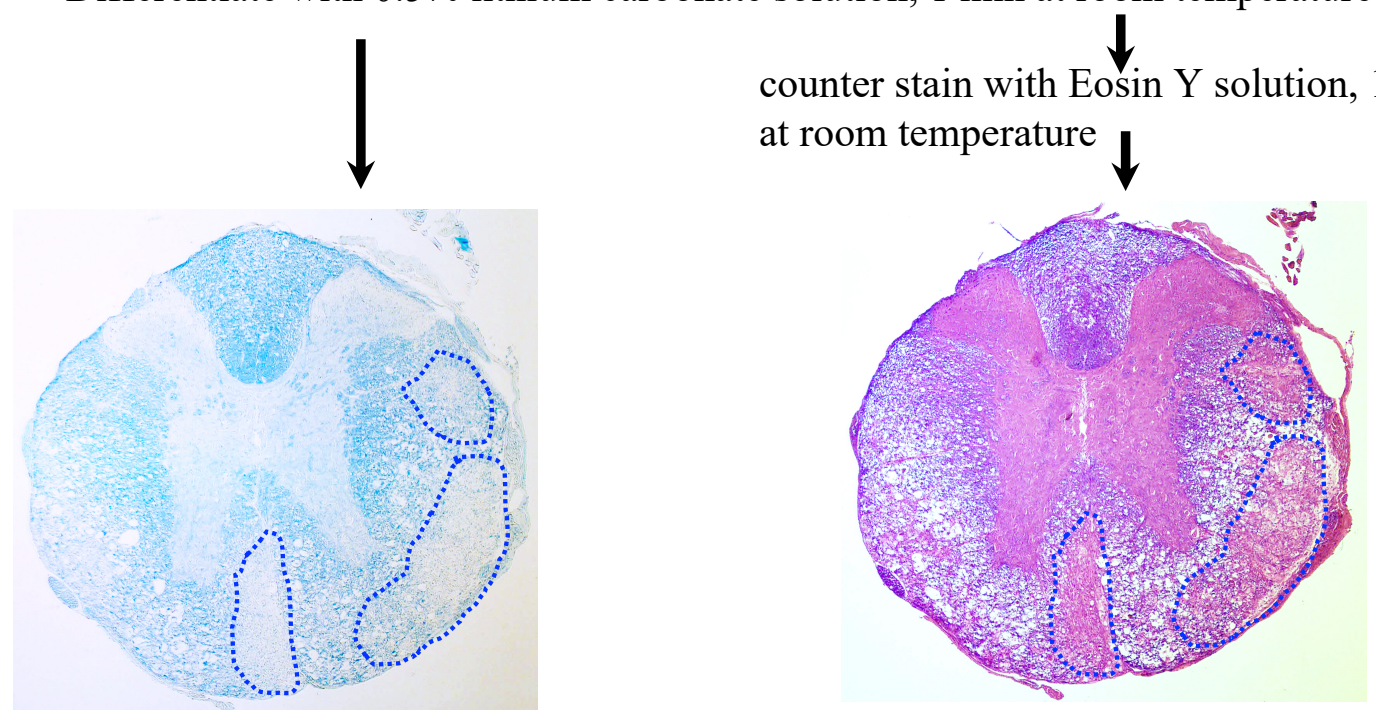

* Yoo IH, Kim MJ, Kim J, Sung JJ, Park ST, Ahn SW. The Anti-Inflammatory Effect of Sulforaphane in Mice with Experimental Autoimmune Encephalomyelitis. J Korean Med Sci 34, e197 (2019). 